Journal of Educational

and Psychological Sciences

Volume (5), Issue (50): 30 Dec 2021

P: $51-68$

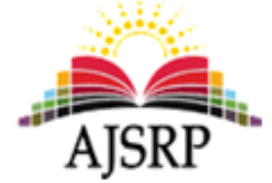

ISSN: 2522-3399

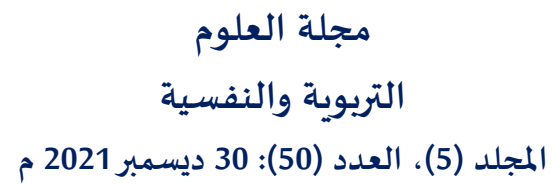

ص: 51 - 58

\title{
The role of the school environment in increasing the academic achievement of basic stage students in Mafraq city schools from the point of view of its
}

\section{teachers}

\section{Muhammad Asbeeh Salameh}

Ministry of Education || Jordan

\begin{abstract}
This study aimed to identify the role of the school environment in increasing the academic achievement of the students of the basic stage in the schools of Mafraq city from the point of view of its teachers. To verify its validity and reliability, it was distributed among the available (30) of the study population, and it was processed statistically using the Statistical Package (SPSS) program, where the study concluded that there is a significant role for the school environment in increasing the academic achievement of the students. Students of the basic stage in Mafraq city schools from the point of view of their teachers, and it was found that there are statistically significant differences at the significance level $(\alpha \leq 0.05)$ in the average responses of the study sample members towards the role of the school environment in increasing the academic achievement of stage students. The primary school in Mafraq city schools according to the study variable (gender, years of experience, educational qualification, specialization), and based on the results of this study, the researcher recommended several recommendations, the most important of which was that primary school teachers in Mafraq schools should rely on the encouragement method instead. About punishment, and it's on teachers b Their plans denied that the student is the focus of the educational process and not following the old curriculum system.
\end{abstract}

Keywords: school environment, increasing academic achievement, Mafraq city schools.

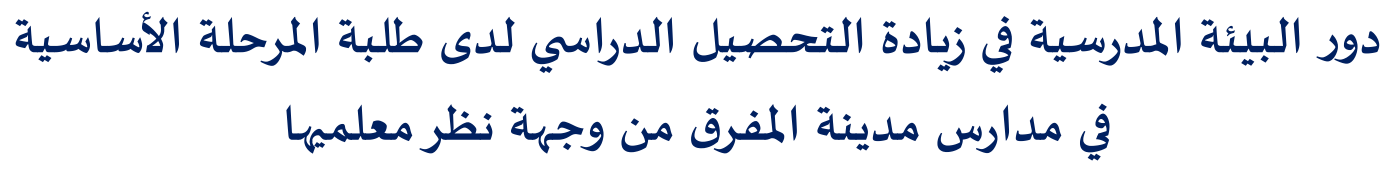

محممد اصببيح سلامه

وزارة التربية والتعليم || الأردن

المستخلص: هدفت هذه الدراسة التعرف إلى دور البيئة المدرسية في زيادة التحصيل الدراسي لدى طلبة المرحلة الأساسية في مدارس مدينة المفرق من وجهة نظر معلمهها"، ولتحقيق هدف الدراسة تم الاعتماد على المنهج الوصفي التحليلي، حيث تم تطوير استبانة مؤلفة

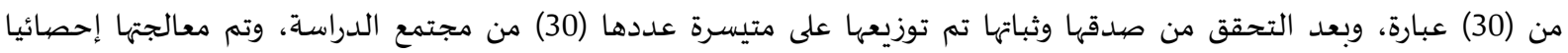

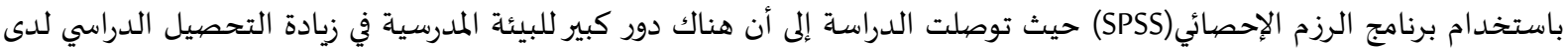

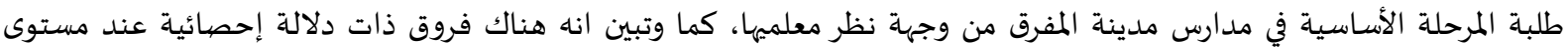
الدلالة (0.05 0 ) في متوسطات استجابات أفراد عينة الدراسة نحو دور البيئة المدرسية في زيادة التحصيل الدراسي لدى طلبة المرحلة الأساسية في مدارس مدينة المفرق حسب متغير الدراسة (الجنس، سنوات الخبرة، المؤهل العلمي، التخصص)، وبناء على نتائج هذه

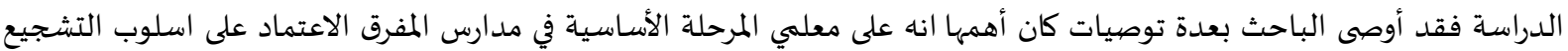
عوضا عن العقاب، وانه على المعلمين بناء خططهم بالاعتماد أن الطالب محور العملية التعليمية وليس اتباع نظام المنهاج القديم. 
تعتبر المدرسة من مؤسسات الريادة في المجتمع نظرا لما تقدماه من خدمات شتى على الصعيدين الفردي

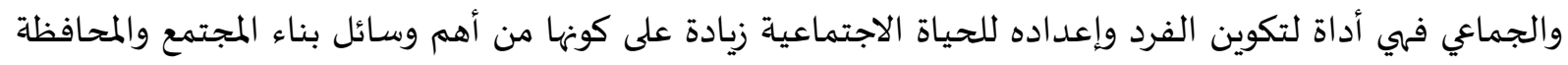

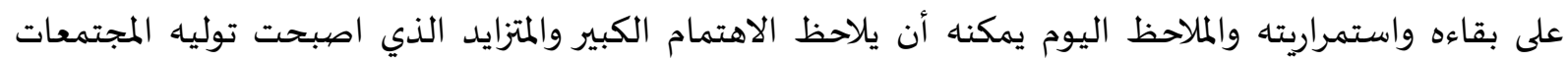

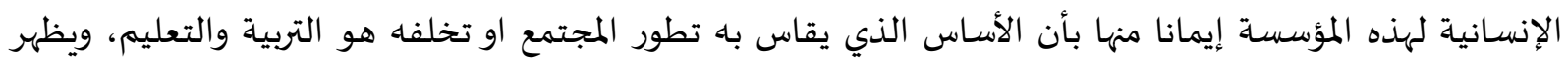

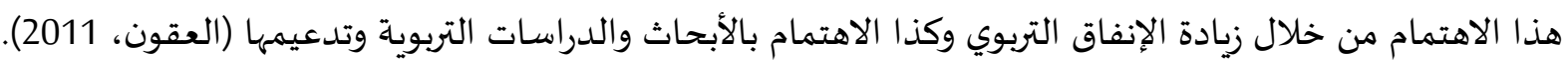

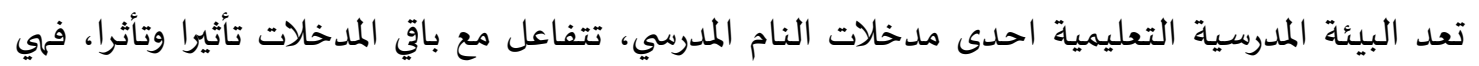

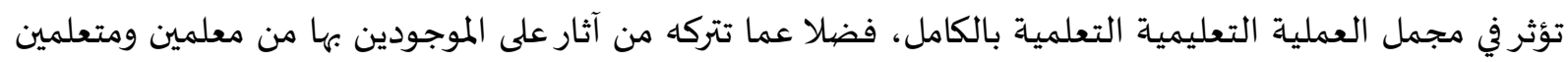

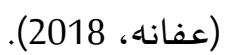

البيئة المدرسية لها دورا مهما في تفجير الطاقات وتنمية المواهب والمهارات، فالبيئة المدرسية الغنية بمصادر التعلم تعد البنية التحتية التي تساعد المدرسة لبلوغ أهدافها، بل وتؤثر على مجمل العملية التعليمية بالكامل، فلا

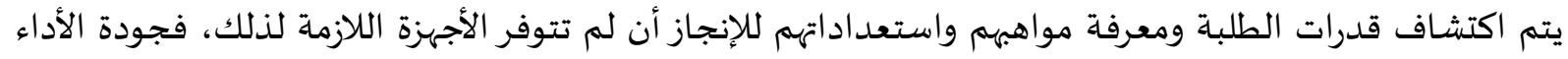

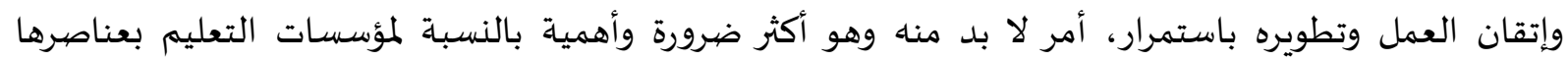

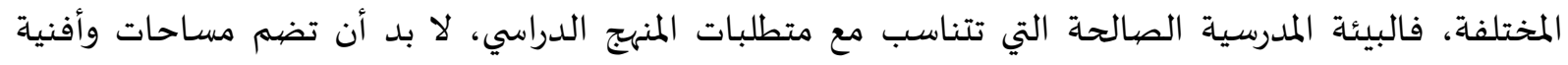
وأماكن للنشاط المدرسي مثل: معامل العلوم والحاسوب والمكتبة المدرسية وملاعب الرياضية، ومقاصف ومتية ومشاريع

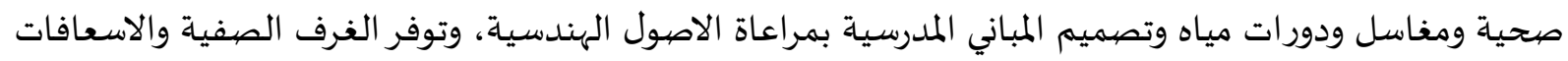
الأولية وتوفروسائل الحماية(جروان، 2016).

تتوقف تنمية دافع الإنجاز للطلاب على توفير المناخ النفسي والاجتماعي السائد في البيئة المدرسية، والمعلم هو أكثر الشخصيات مقدرة على خلق المناخ المدرسي الملائم لرفع مستوى دافع الإنجاز لطلابه من خلال المان حماساه

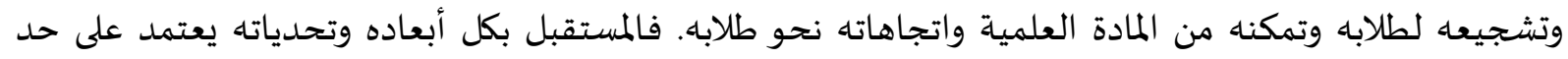

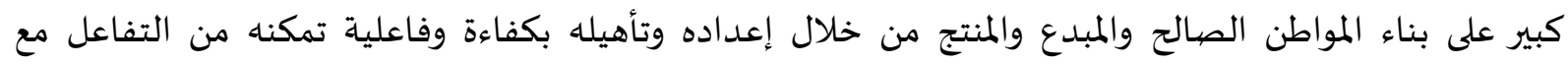

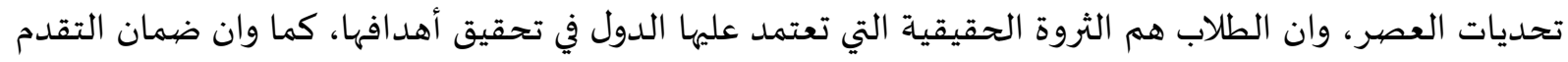

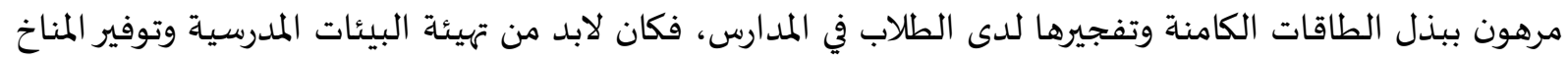

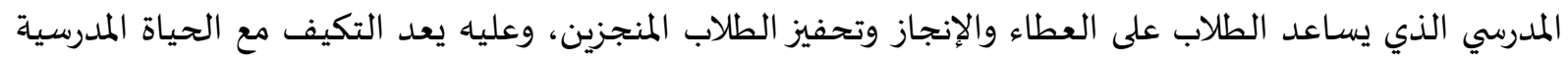

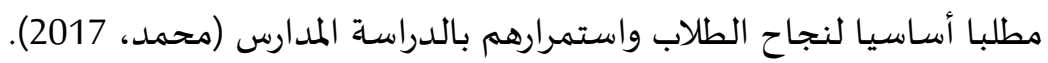

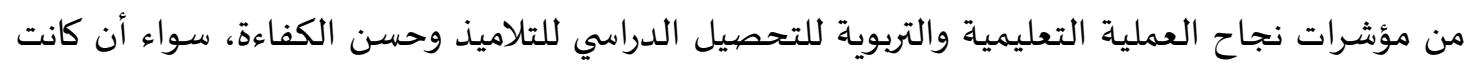

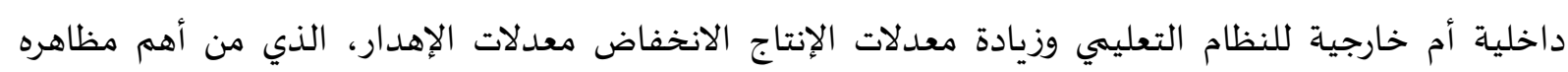

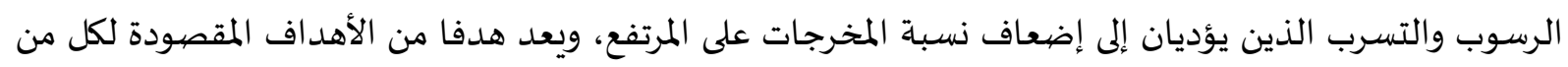

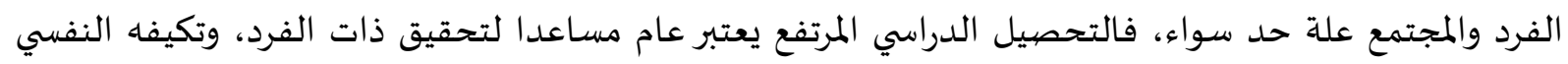
الاجتماعي وإحساسه بالرضى عن نفسه وبالسعادة، ونتيجة لإنجازهه وتحصيله الدراسي المرتفع الذي فئي حققه.(مضوي، 2012) 
وبناء على ما سبق فقد تبين أن هناك دور مهم للبيئة المدرسية في العلمية التعليمية وفي نفس الوقت هناك

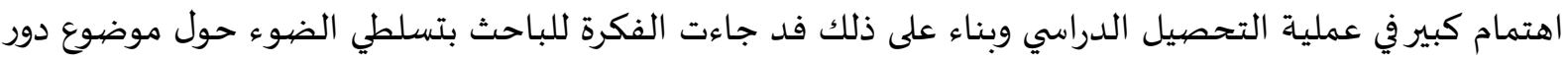

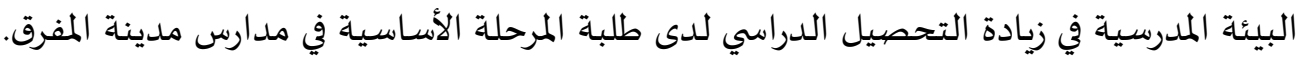

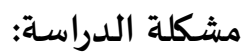

تعد البيئة المدرسية مهمة جدا للمعلم والطالب حيث أن البيئة المدرسية تلعب دور كبير في عملية التعلم

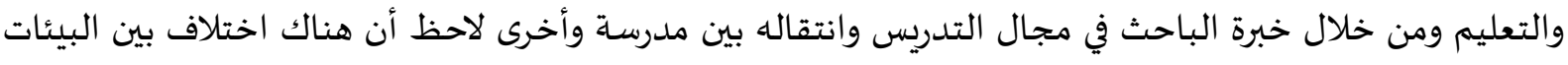

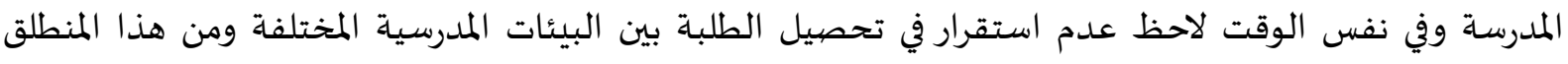

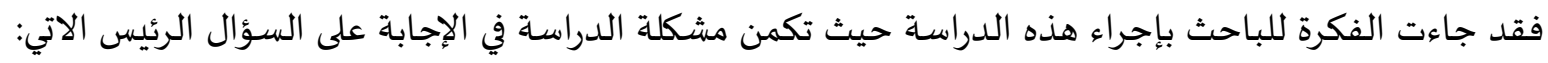

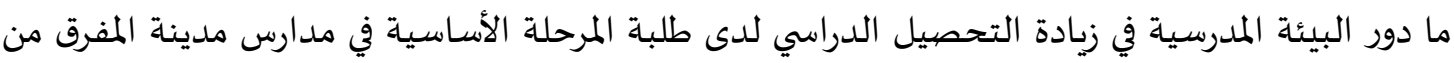

وجهاة نظر معلميها؟ ويتفرع من السؤال الرئيس الأسئلة الفرعية الآتية:

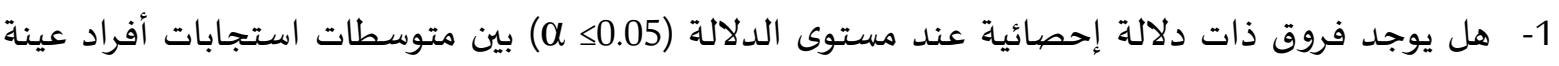

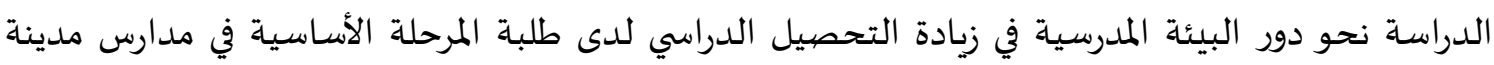
المفرق حسب متغير الجنس. 2- هل يوجد فروق ذات دلالة إحصائية عند مستوى الدلالة (0.05 م) بين متوسطات استجابات أفراد عينة

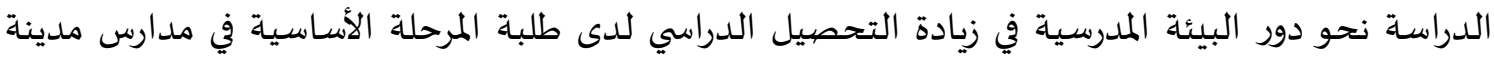

$$
\text { المفرق حسب متغير سنوات الخبرة. }
$$

3- هل يوجد فروق ذات دلالة إحصائية عند مستوى الدلالة (0.05 ه ب) بين متوسطات استجابات أفراد عينة الدراسة نحو دور البيئة المدرسية في زيادة التحصيل الدراسي لدى طلبة إلماتية المرحلة الأساسية في مدارس مدينة

$$
\text { المفرق حسب متغير المؤهل العلمي. }
$$

4- هل يوجد فروق ذات دلالة إحصائية عند مستوى الدلالة (0.05 ه ب) بين متوسطات استجابات أفراد عينة الدراسة نحو دور البيئة المدرسية في زيادة التحصيل الدراسي لدى طلدية إلبة المرحلة الأساسية في مدارس مدينة

المفرق حسب متغير التخصص.

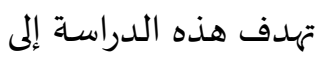

1- التعرف على دور البيئة المدرسية في زيادة التحصيل الدراسي لدى طلبة المرحلة الأساسية في مدارس مدينة

$$
\text { المفرق من وجهة نظر معلميها. }
$$

2- التعرف إذا كان هناك فروق ذات دلالة إحصائية بين متوسطات استجابات أفراد عينة الدراسة نحو دور

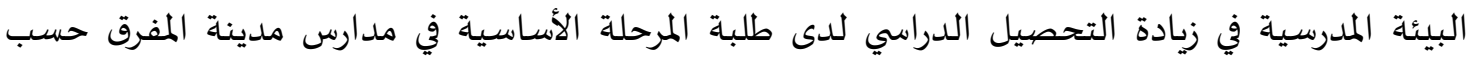

3- التعرف إذا كان هناك فروق ذات دلالة إحصيائية بين متوسطات استجابات أفراد عينة الدراسة نحو دور

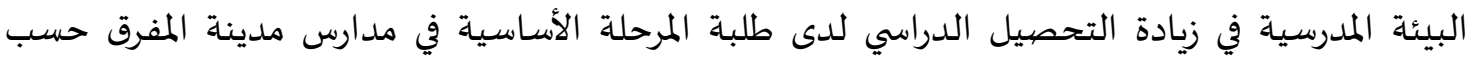

$$
\text { متغير سنوات الخبرة. }
$$


4- التعرف إذا كان هناك فروق ذات دلالة إحصائية بين متوسطات استجابات أفراد عينة الدراسة نحو دور

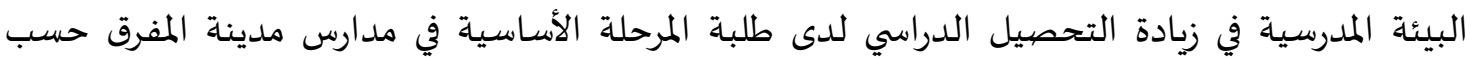

$$
\text { متغير المؤهل العلمي. }
$$

5- التعرف إذا كان هناك فروق ذات دلالة إحصائية بين متوسطات استجابات أفراد عينة الدراسة نحو دور

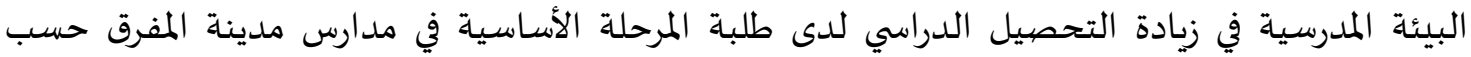

متغير التخصص.

أهمية الدراسة

تستمد الدراسة أهميتها من الجانبين النظري والتطبيقي، كما يلي:

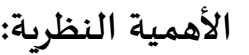

تنبع أهمية الدراسة من أهمية البيئة المدرسية وكذلك التحصيل الدراسة ذاتهما، ودورهما المهم في العملية

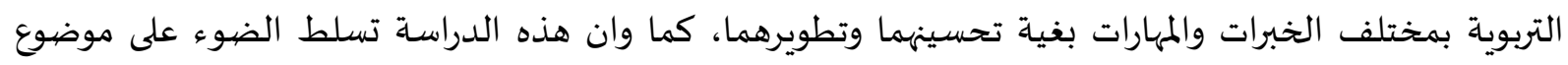
البيئة المدرسية وكذللك التحصيل الدراسي وتناولهما في الشرح والتحليل من خلال الاطار النظري، كما وتساهم هذهاه الدراسة في تسليط الضيوء على دور البيئة المدرسية في زيادة التحصيل الدراسي في إيجاد معلومات نظرية مهيماه للباحثين في كونه يتوقع منها أن تشكل مادة أدبية تُثري المكتبة العربية بمادة نظرية وعملية عن المبادية البيئة المدرسية وكذلك التحصيل الدراسي.

\section{الأهمية التطبيقية:}

تساعد الدراسة المعلمين وصناع القرار على الاهتمام بالبيئة المدرسية والتغلب على المعيقات والصعوبات

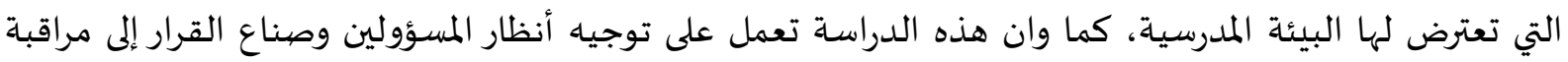

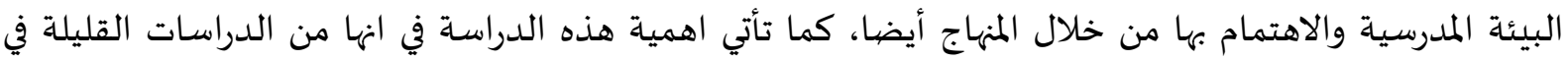

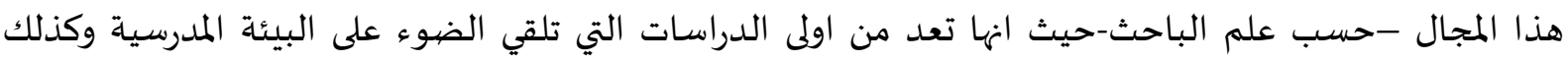

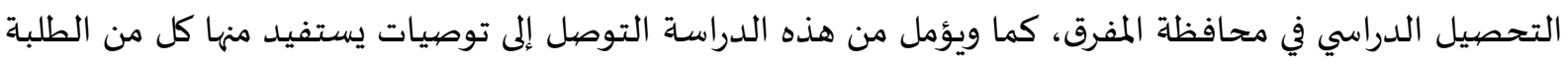

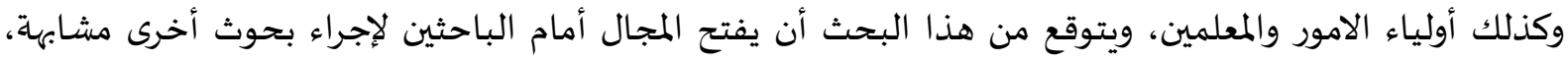

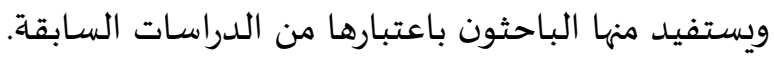

حدود الدراسة

تقتصر الدراسة على الحدود الآتية:

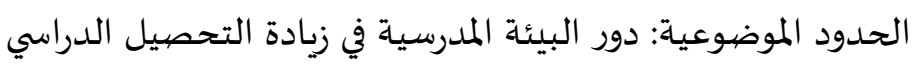

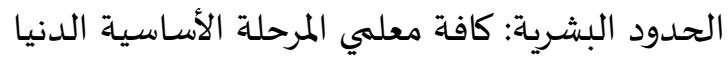

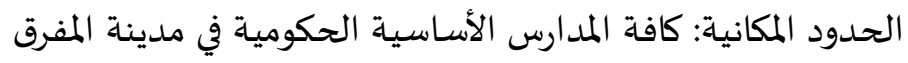

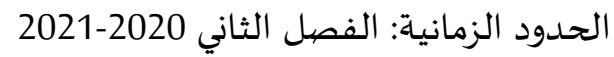

مصطلحات الدراسة

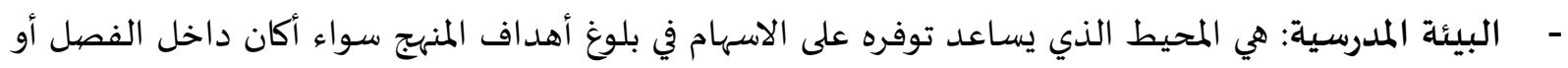

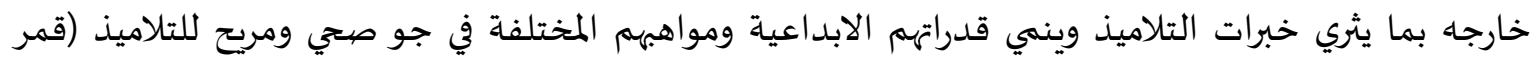

الدين وآخرون، 2010). 
- التحصيل الدراسي: هو بلوغ مستوى معين من الكفاءة الدراسية ويفسره لنا درجة إدراك الطالب لكفاءته بالسلب أو بالإيجاب، ويحدد اختبارات التحصيل الموضوعة المستخدمة لمون (برور، 2010).

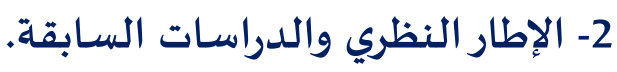

أولاً - الإطار النظري.

مفهوم التحصيل الدراسي:

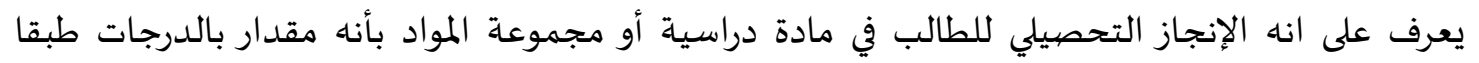

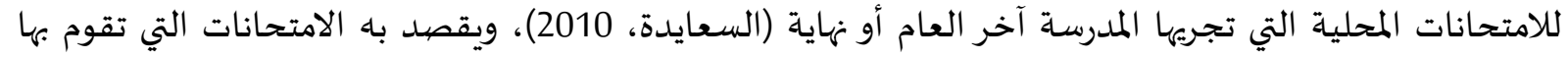
المدرسة لمعرفة مقدار مدى استفادة المتعلمون من المواد التي يدرسوها لتدارك ما يبدو منهم من ضعف وتكون إما شهرية أو فصلية أي كل شهرين أو ثلاث أو أكثر(الأسطل، 2010)، ويعرفه الحموري(2010) على ملى انهاد كل مان ما يكتسبه الطالب من معارف ومهارات واتجاهات وميول وقيم وأساليب وتفكير وقدرات على حل مشكلات، نتيجة لدراسة ما هون الهو

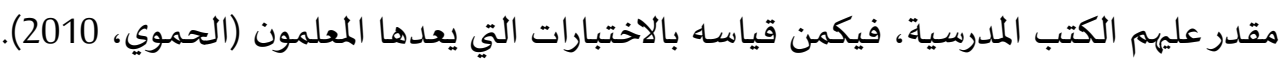

أهمية التحصيل الدراسي

تبرز أهمية التحصيل الدراسي بالنسبة للفرد هدفا من أهدافه الأساسية، يتوفق على تحقيقه بنجاح

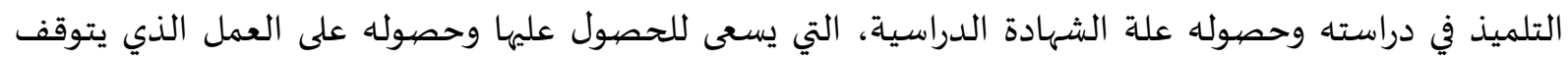

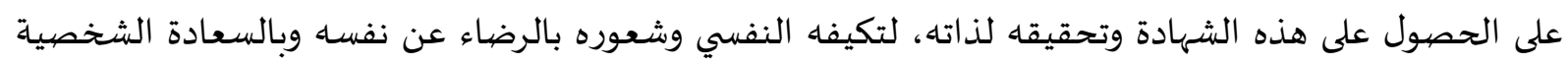

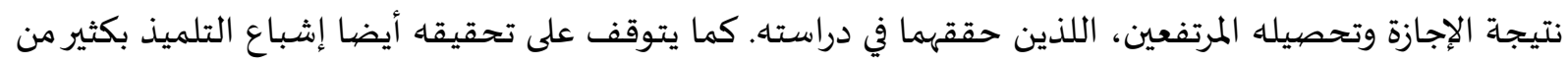

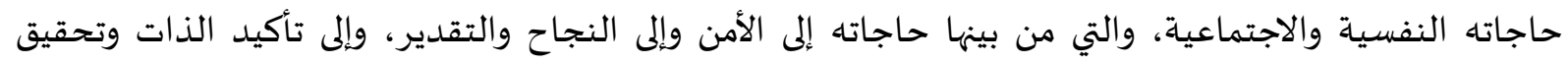

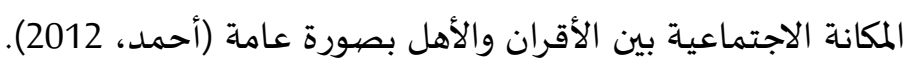

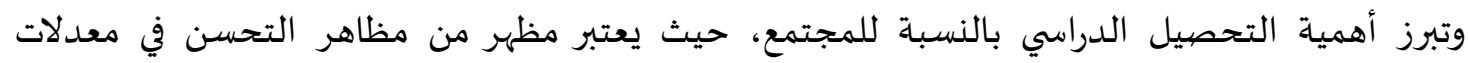

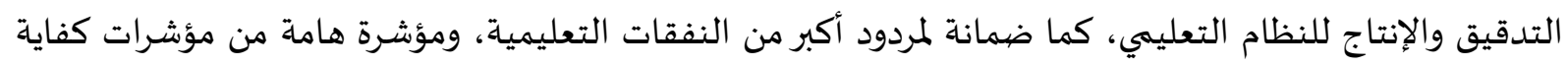

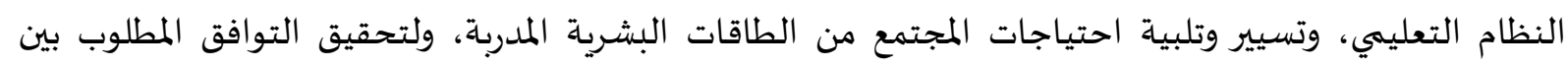

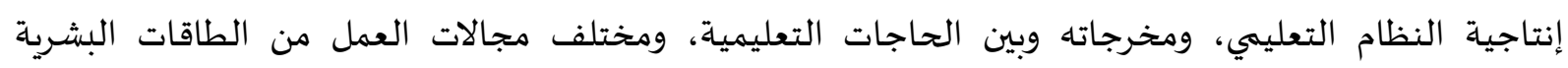
(محمود، 2013).

\section{مفهوم البيئة المدرسية}

تعرف البيئة المدرسية بأهها الإطار العام الذي ينصهر داخله مكونات العملية التربوية المختلفة، ودرجة

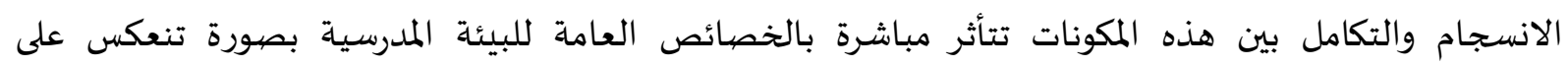

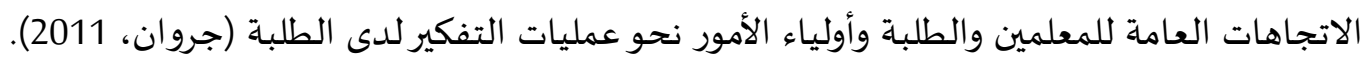

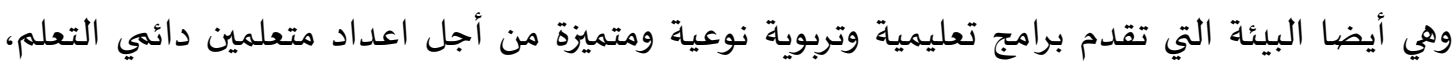

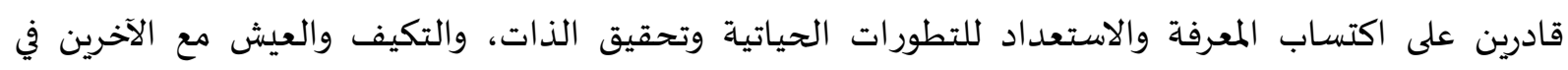

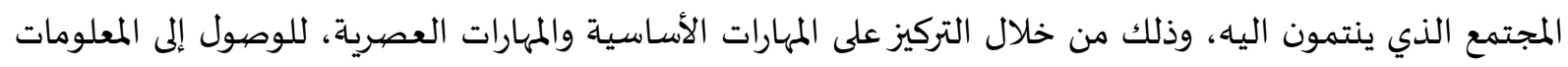
والمهارات العقلية (الأهلي، 2015). 
عناصر البيئة المدرسية:

تتكون البيئة المدرسية من العديد من العناصر أهماها حجرة المصادر التعليمية فقد أدخلت حديثا على

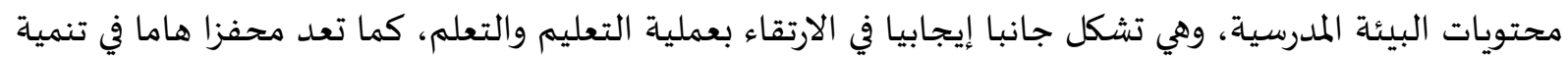

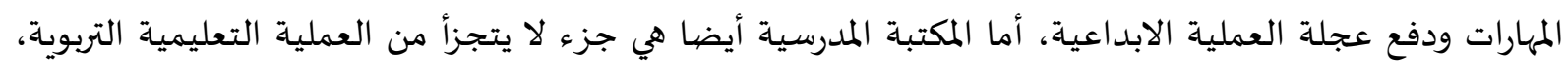

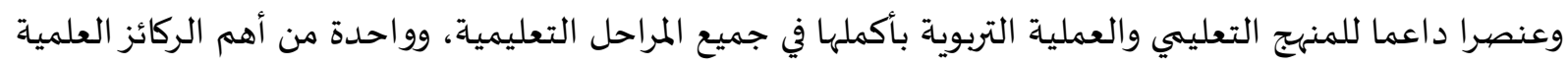

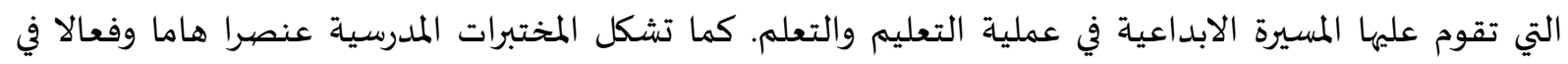
مسيرة المتعلمين التعليمية، وعلى وجه الخصوص المرحلة الثانوية، فهي تهيئ الجو المريح لإجراء التجارب التمابل المخبرية

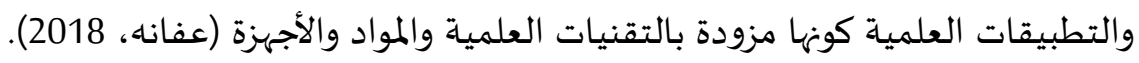

ثانياً- الدراسات السابقة: - دراسة المالكي (2018) هدفت الدراسة الحالية إلى معرفة دور البيئة الأسرية والمدرسية في تعزيز التحصيل

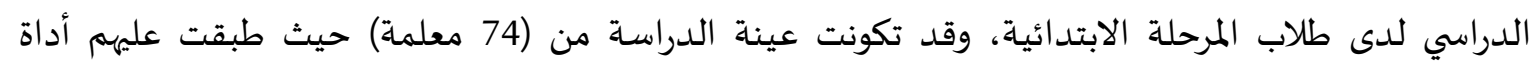

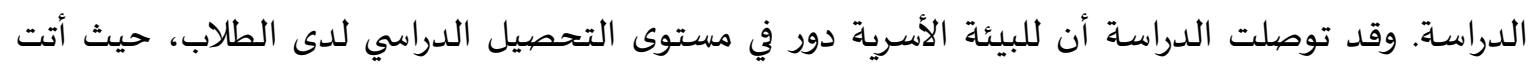

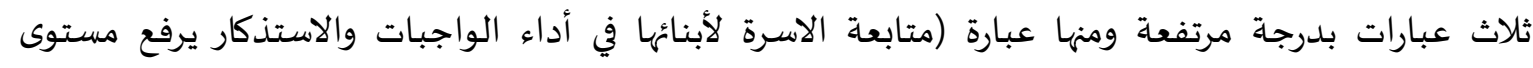

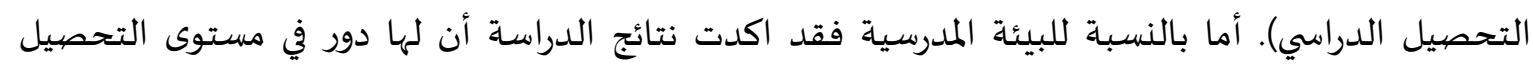

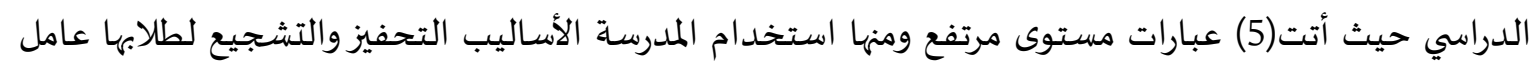

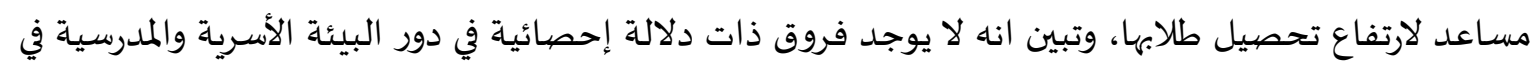

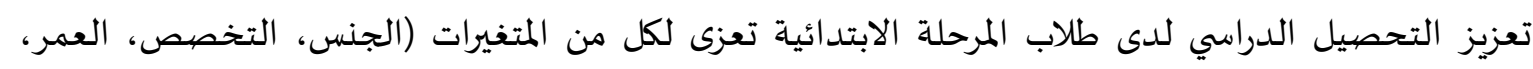

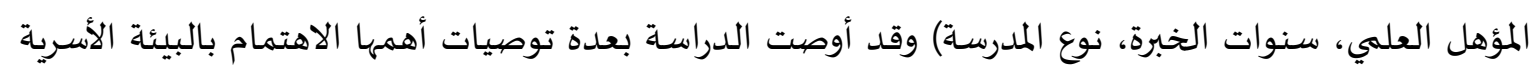
والمدرسية حيث أنهما يعتبران من محددات التحصيل الدراسي.

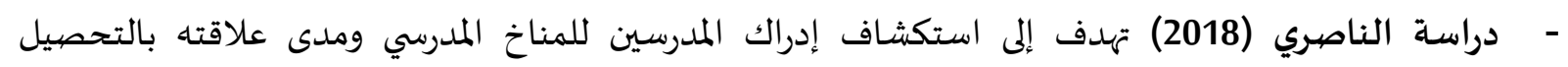

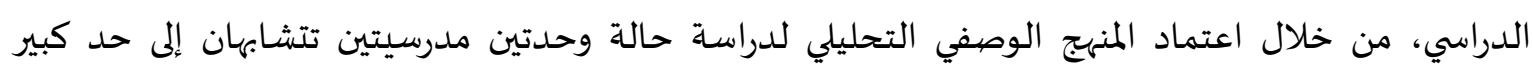

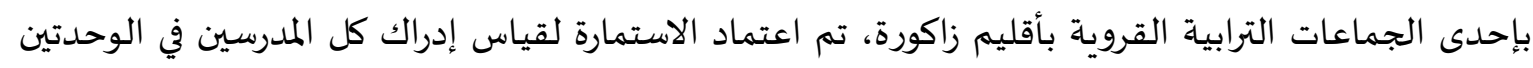

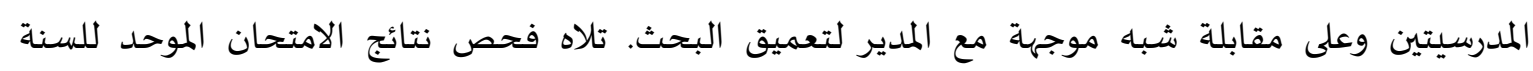

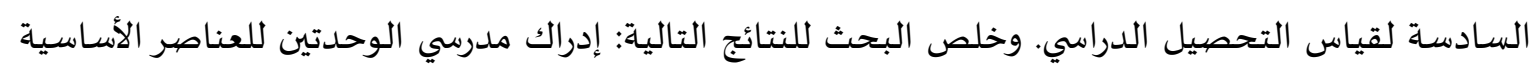

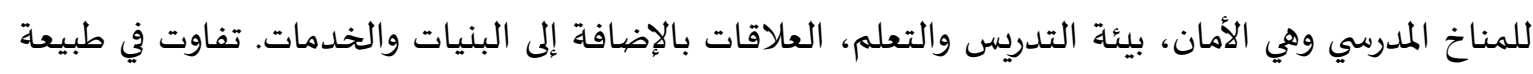

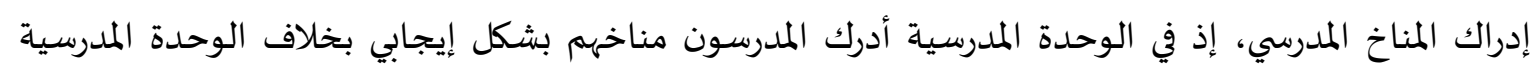

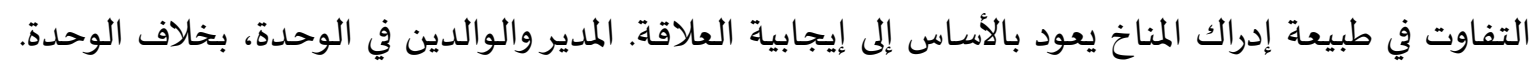

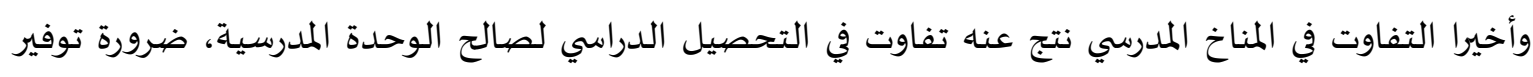

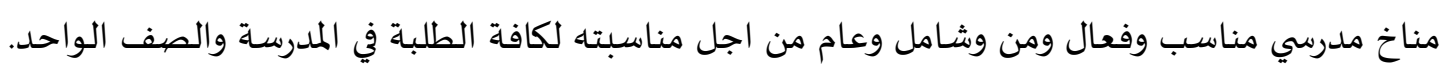

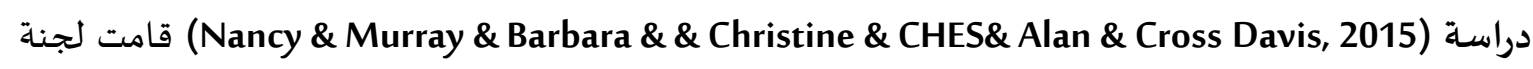
متعددة التخصصيات من الباحثين الصحيين بالبحث في الأدبيات المتعلقة بالتحصيل الأكاديمي وعناصر نموذج

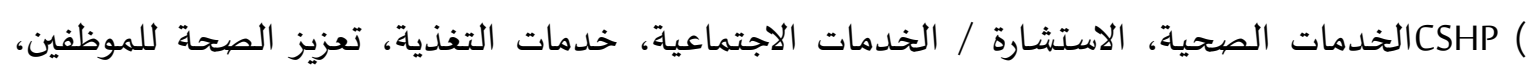

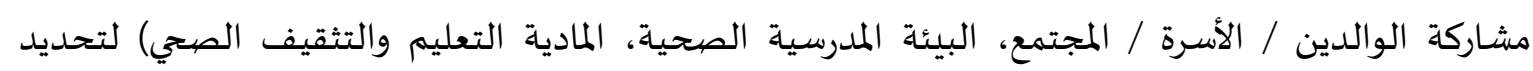

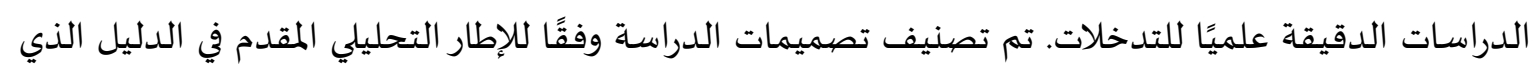


طوره فريق عمل الخدمات الوقائية المجتمعية .النتائج: يوجد أقوى دليل من التقييمات الدقيقة علميًا للتأثير

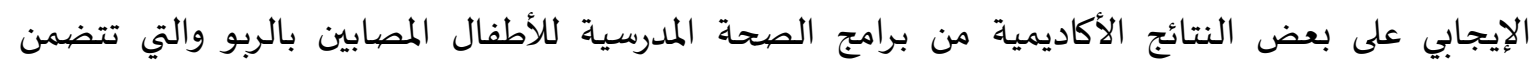

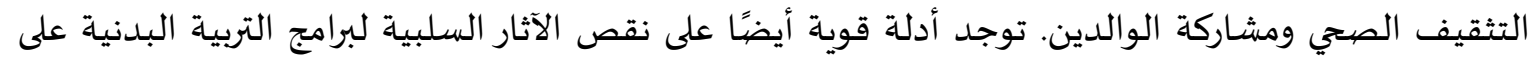

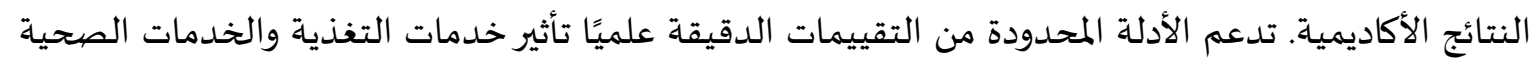

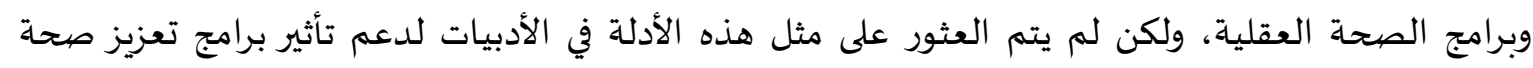

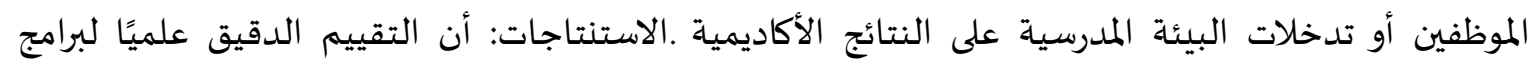

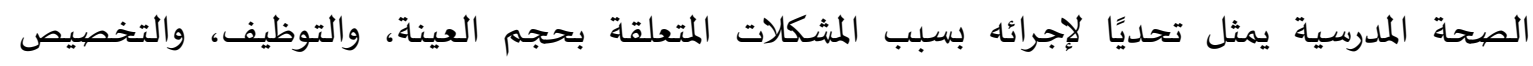

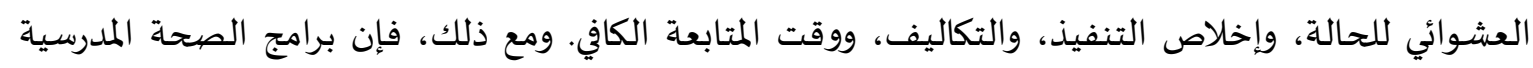

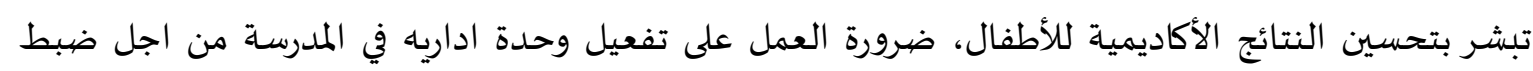

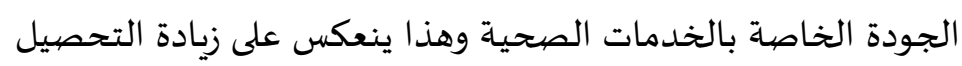

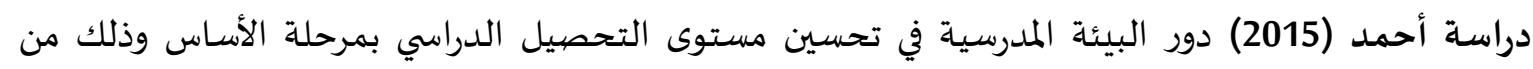

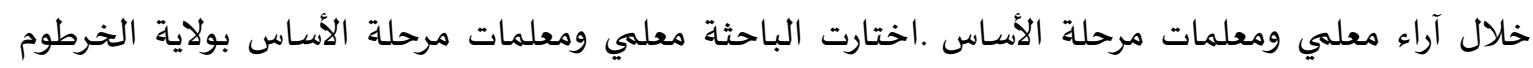

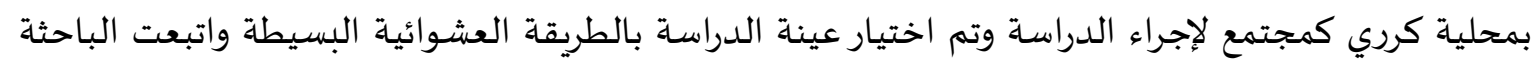

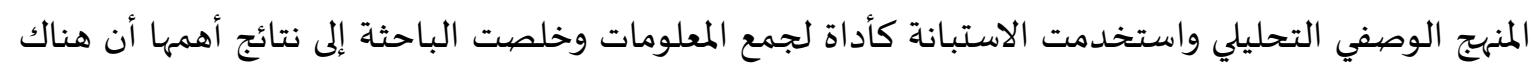

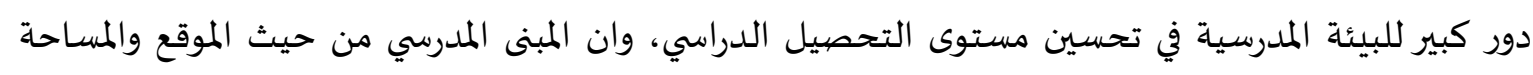

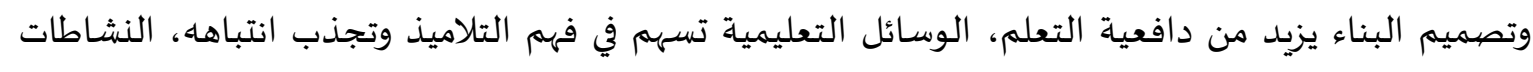

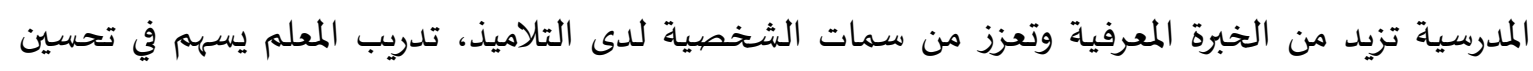

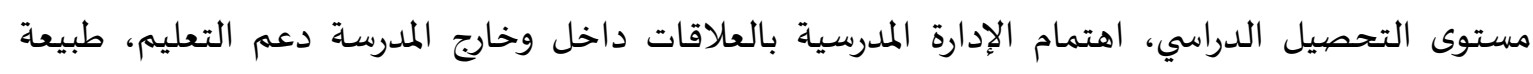

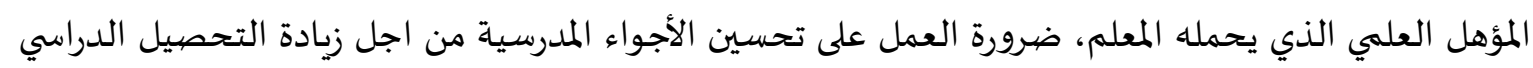

لدة الطلبة.

دراسة (Gietz \& mclntosh, 2014) فحصت هذه الدراسة تصورات الطلاب عن بيئتهم المدرسية (على وجه

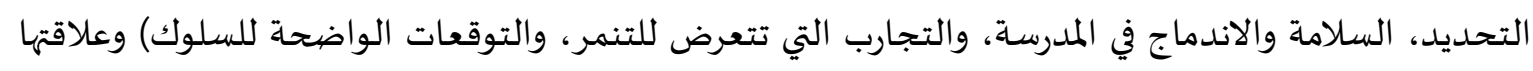

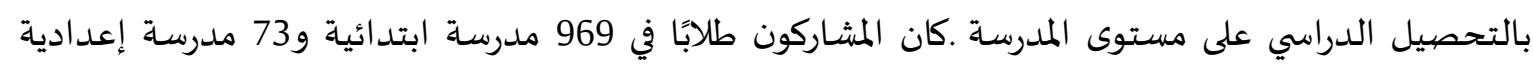

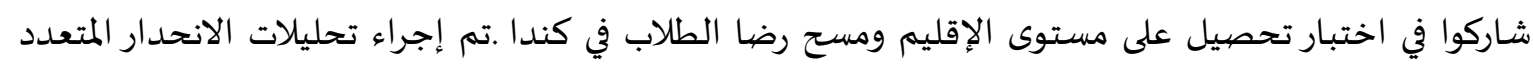

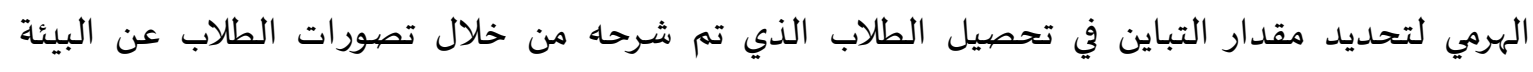

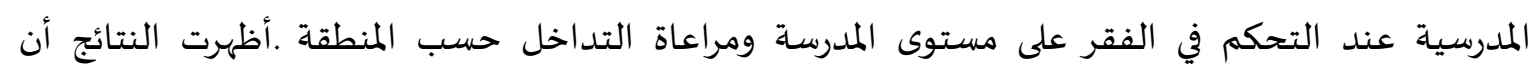

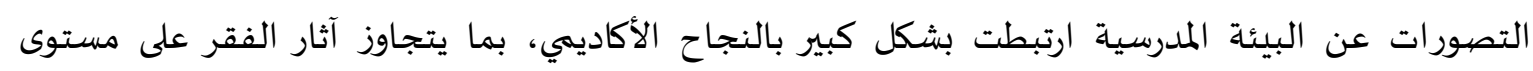

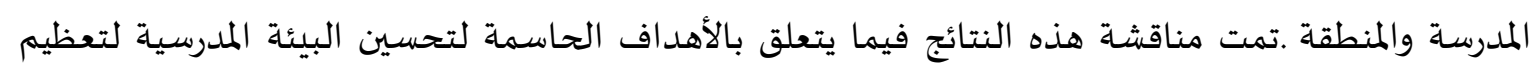
التحصيل الدراسي، ومن ضمن التوصيات كان على القائمين على المدارس ابعاد الطلاب عن السلوكيات التي لتصني

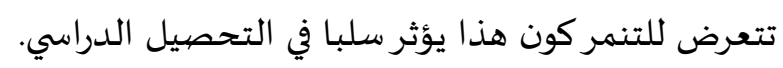
دراسة (Lawrence, 2012) هدفت إلى معرفة العلاقة بين البيئة المدرسية والإنجاز الأكاديمي لطلبة الصفي الصفئ

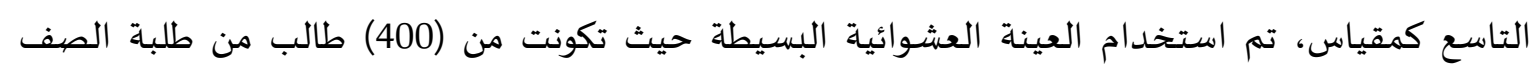

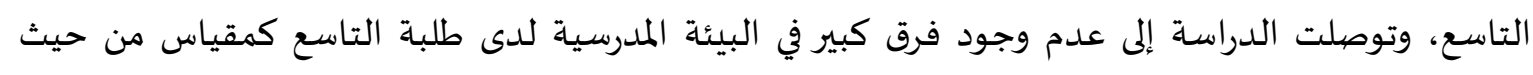

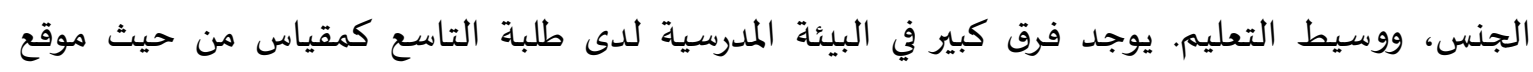

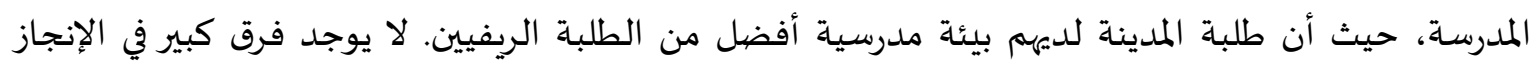


الأكاديمي لطلبة التاسع كمقياس من حيث الجنس. يوجد فرق كبير في الإنجاز الأكاديمي لدى طلبة التاسع القياسية من حيث التعليمات المحلية ومكانة المدرسة، ومن اهم التوصيات العمات العمل على الاستمرار في تحسين البيئة المدرسية كون هذا يساعد على ارتفاع الإنجاز الأكاديمي. دراسة (Grete, 2013) استقصت هذه الدراسة التحصيل الدراسي وتحديد التأثير الفردي والسياقي للبيئة المدرسية للمراهقين من حيث التنمر والعلاقات مع زملأهم في الفصل ودعم المعلم على التحصيل الدراسي.

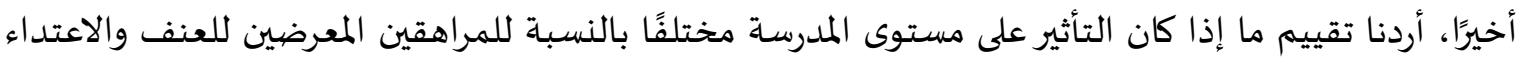

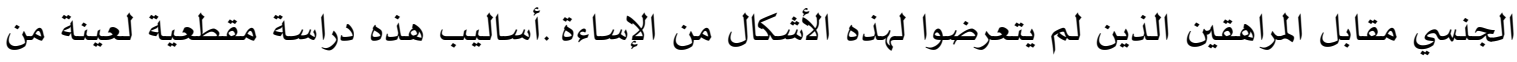

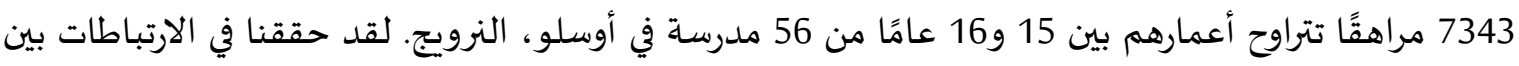

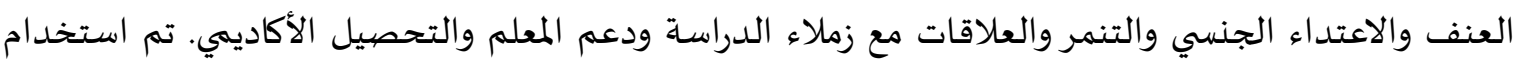

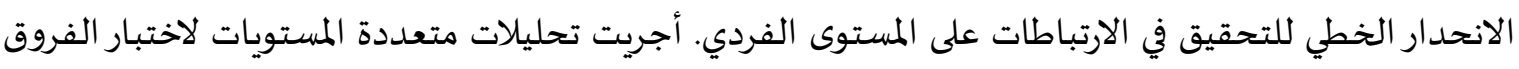

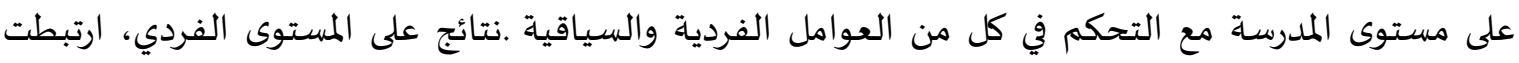

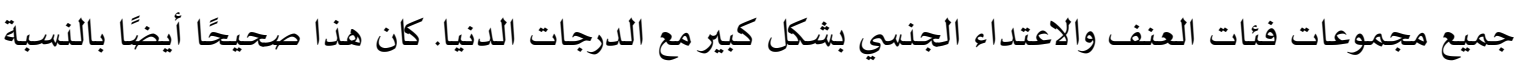

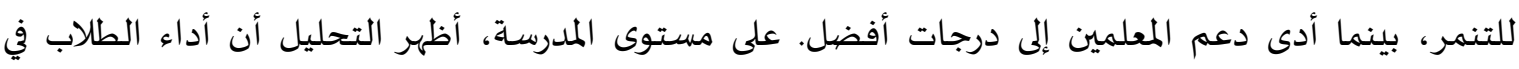

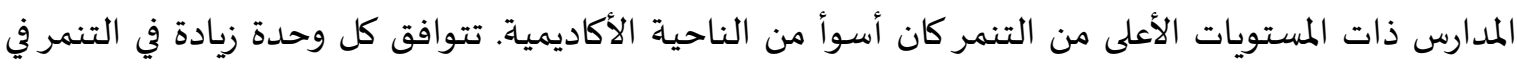

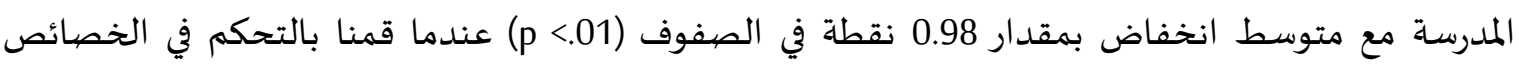

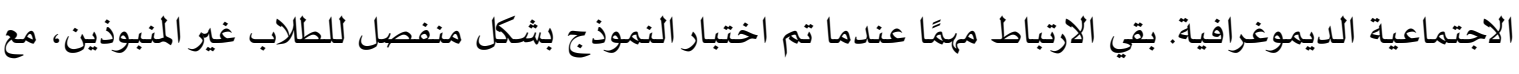

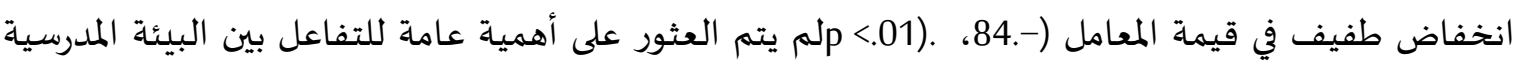

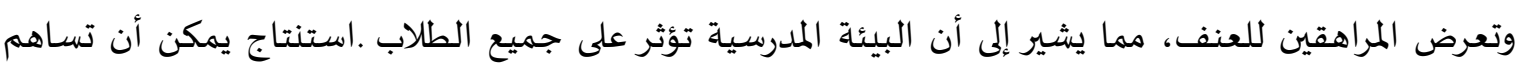

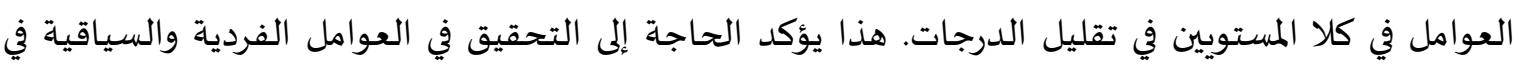

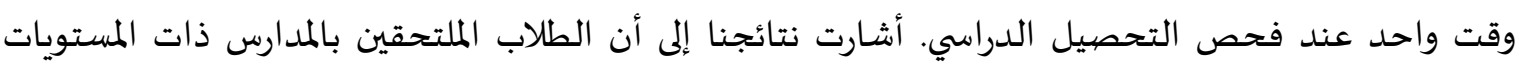

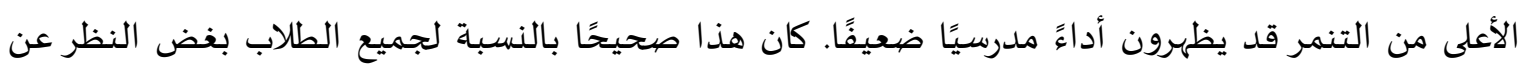
التعرض السابق للعنف والاعتداء الجنسي. ومن التوصيات العمل على بذل جهود وقائية وتركز على الفئئات الضعيفة التعرض الضيف

دراسة الخليفة (2010) هدف هذه الدراسة للتعرف على علاقة البيئة المدرسية بكل جوانها بالتحصيل

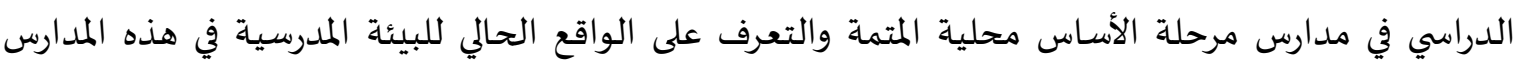

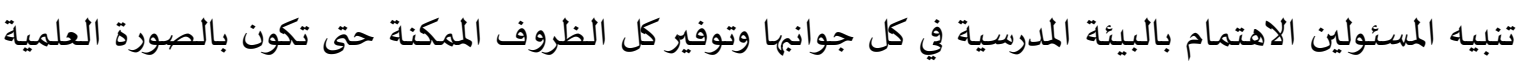

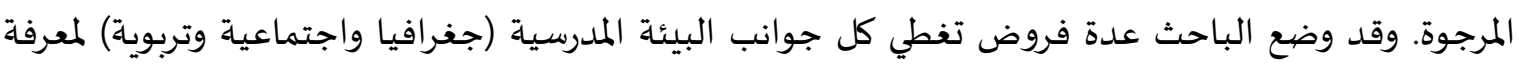

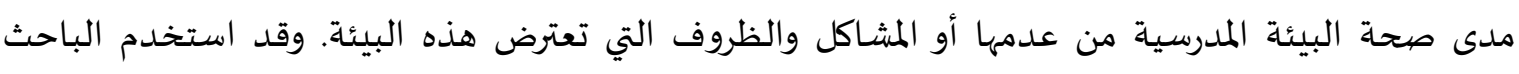

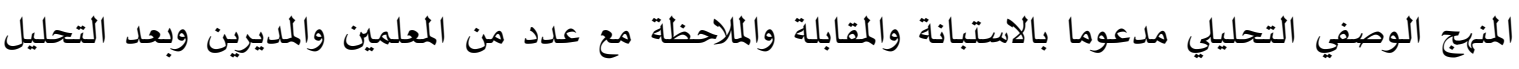

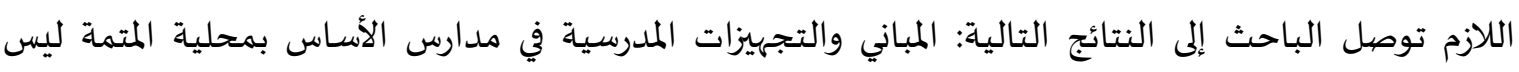

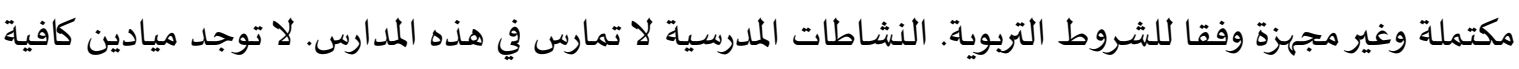

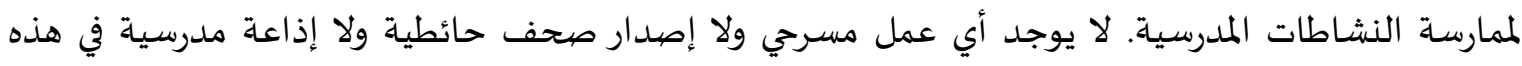

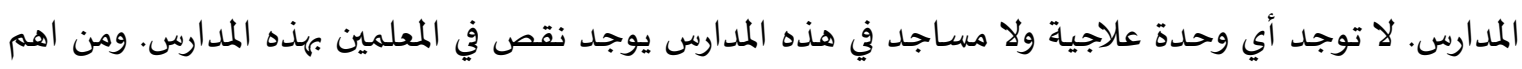

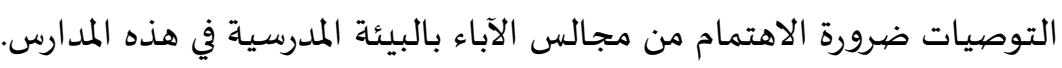


دراسة (Wang \& Holcombe, 2010) فحص هذا البحث المدى القصير العلاقات بين تصورات طلاب المدارس

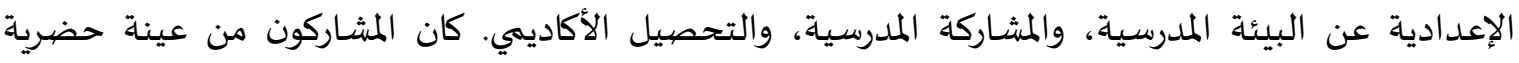

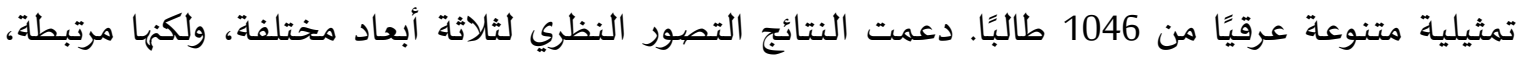

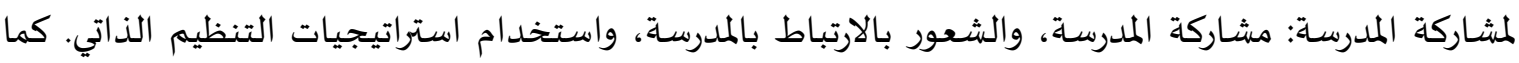

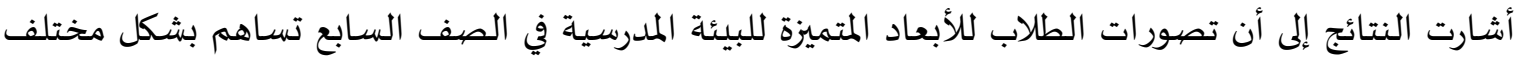

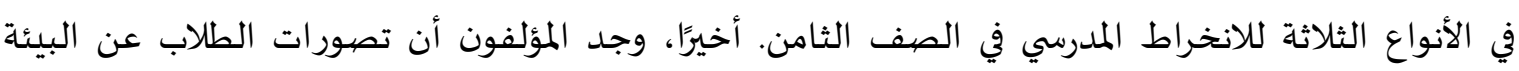

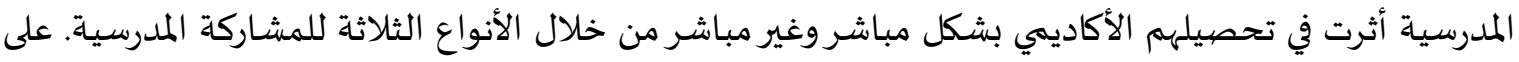

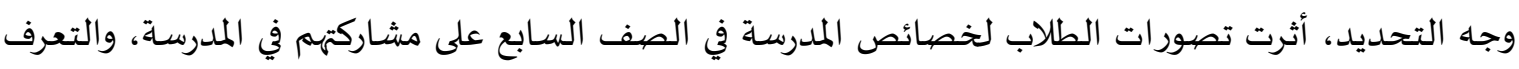

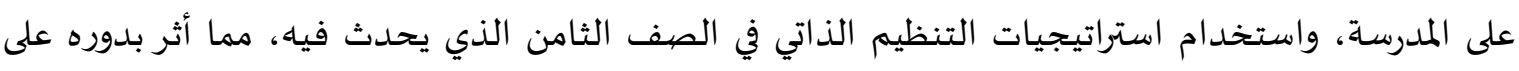

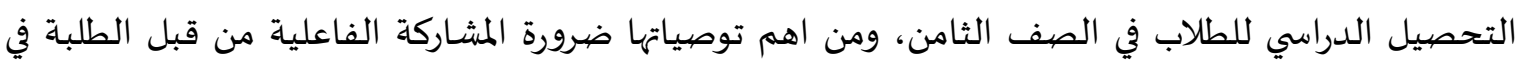

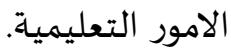

3- منهجية الدراسـة وإجراءاتها.

منهجية الدراسـة:

من اجل تحقيق أهداف الدراسة تم استخدام المنهج الوصفي الميداني والذي يعرف بأنه طريقة في البحث

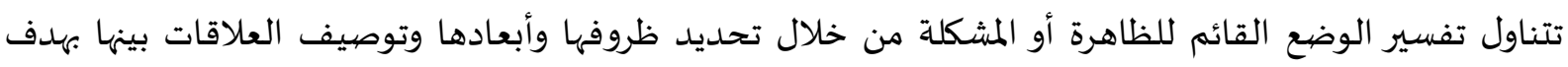

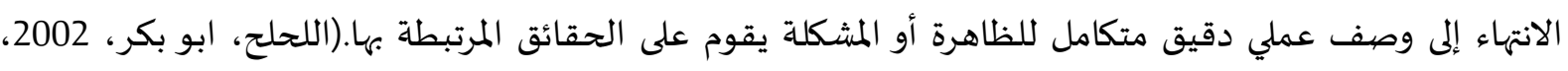

\section{مجتمع الدراسة وعينتها:}

تكون مجتمع الدراسة من جميع معلمي المدارس الأساسية في مدينة المفرق حيث تم توزيع عليهم استبانة بعد حوسبتها الكترونياً، حيث تم اختيار منهم عينة متيسرة بحجم (40) معلم ومعلمة تم توزيع عليهم استبانة استرد

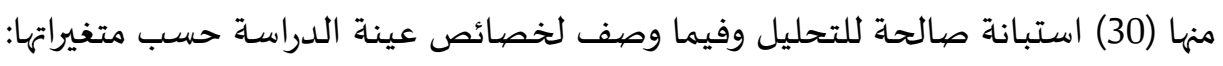

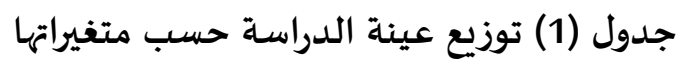

\begin{tabular}{|c|c|c|c|}
\hline النسبة المئوية & العدد & فئات المتفير & المتغير \\
\hline 50.0 & 15 & ذ ذكور & \multirow{3}{*}{ الجنس } \\
\hline 50.0 & 15 & اناث & \\
\hline 100.0 & 30 & المجموع & \\
\hline 21.1 & 6 & أقل من 5 سنوات & \multirow{5}{*}{ سنوات الخبرة } \\
\hline 33.3 & 10 & من5-9 سنوات & \\
\hline 33.3 & 10 & 15-10 سنة & \\
\hline 12.3 & 4 & اكثر من 15 سنة & \\
\hline 100.0 & 30 & المجموع & \\
\hline
\end{tabular}


المجلة العربية للعلوم ونثر الأبحاث ـ مجلة العوم التربوية والنفسية ـ المجلد الخامس ـ العدد الخمسون ـ ديسمبر 2021م

\begin{tabular}{|c|c|c|c|}
\hline النسبة المئوية & العدد & فئات المتفير & المتغير \\
\hline 26.7 & 8 & دبلوم & \multirow{4}{*}{ المؤهل العلمي } \\
\hline 50.0 & 15 & بكالوريوس & \\
\hline 23.3 & 7 & دراسـات عليا & \\
\hline 100.0 & 30 & المجموع & \\
\hline 50.0 & 15 & تربية ابتدائية & \multirow{4}{*}{ التخصص } \\
\hline 16.7 & 5 & انجليزي & \\
\hline 33.3 & 10 & أخرى & \\
\hline 100.0 & 30 & المجموع & \\
\hline
\end{tabular}

أداة الدراسـة:

قام الباحث بإعداد أداة الدراسة (الاستبانة) وذلك بعد مراجعة أدبيات الدراسة والدراسات السابقة ذات

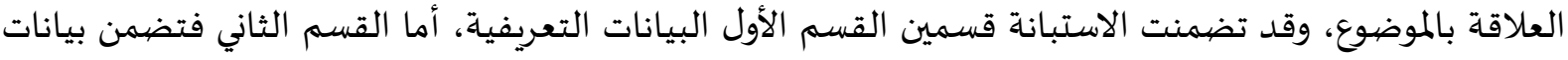
متغيرات الدراسة حيث بلغت عدد عبارات الأداة (20) عبارة، وقد صمم على أساس مقياس ليكرت (Likert Scale)

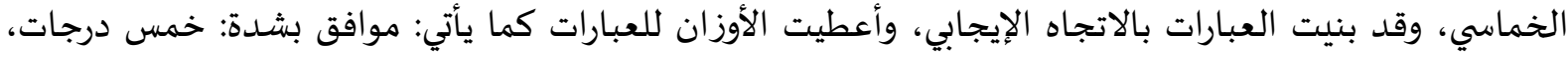

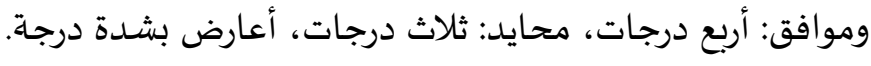

صدق الأداة:

لقد تم التحقق من صددق الأداة عن طريق عرضها على مجموعة من المحكمين ذات الاختصاص والخبرة في

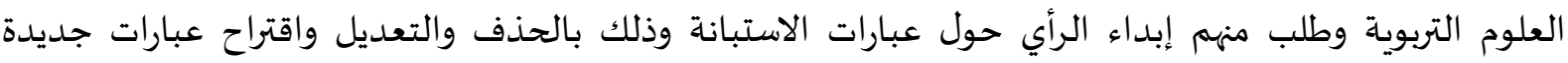
ومناسبة الأداة لموضوع الدراسة، وبناء على ملاحظات المحكمين تم تعديل أداة الدراسة فأصبحت بصهورتها النهائية

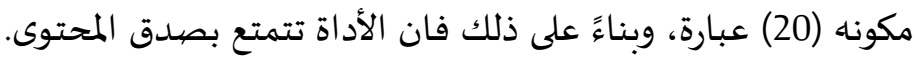

ثبات الأداة:

من استخراج معامل الثبات قام الباحث باستخدام معادلة الفا كرونباخ فقد بلغ معامل الثبات (0.92)

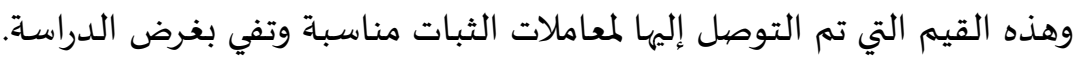

$$
\text { إجراءات الدراسـة: }
$$

لقد تم إجراء هذه الدراسة وفق الخطوات الآتية:

$$
\begin{aligned}
& \text { 1. إعداد أداة الدراسة بصورتها النهائية } \\
& \text { 2. تحديد أفراد مجتمع الدراسة } \\
& \text { 3. اختيار عينة الدراسة } \\
& \text { 4. توزيع الاستبيانات على عينة الدراسة الدانة }
\end{aligned}
$$

5. تفريخ البيانات وإدخال البيانات إلى الحاسب وميناتيات ومعالجتها إحصائيا باستخدام البرنامج الإحصائية للعلوم 
ولتحديد درجة الموافقة فقد حدد الباحث ثلاثة مستويات هي (قليل، متوسط، كبير) بناءً على المعادلة

الحد الأعلى للمقياس (5) - الحد الأدنى للمقياس (1)

عدد الفئات المطلوبة (3) (a)

(طول الفئة) 1.33 = 3=(1-5)

ومن ثم إضافة الجواب (1.33) إلى نهاية كل فئة.

والجدول (2) يوضح المقياس في تحديد مستوى الدور للمتوسط الحسابي عند التعليق على المتوسطات

جدول (2) مقياس تحديد المديات للمتوسط الحسابي والتقديرات اللفظية للدور المقابل لها

\begin{tabular}{|c|c|}
\hline حجم الدور & المتوسط الحسـابي \\
\hline قليل & $2.33-1$ \\
\hline متوسط & $3.67-2.34$ \\
\hline كبير & $5-3.68$ \\
\hline
\end{tabular}

المعالجة الإحصيائية:

وبعد جمع البيانات وترميزها ومعالجتها بالطرق الإحصائية المناسبة، وذلك باستخدام البرنامج الإحصيائي للعلوم الاجتماعية SPSS، فقد استخدم الباحث التكرارات والمتوسطات الحسابية والانحرافات المعيارية، ومعادلة كرونباخ الفا، واختبار تحليل التباين الاحادي، واختبار (ت) لعينتين مستقلتين.

4- عرض نتائج الدراسـة ومناقشتها.

النتائج المتعلقة بالسؤال الرئيسي: "ما دور البيئة المدرسية في زيادة التحصيل الدراسي لدى طلبة المرحلة

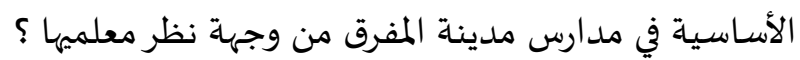

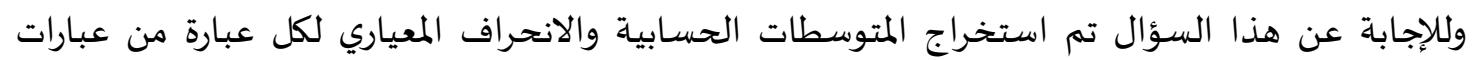
الأداة، والجداول التالية تبين ذلك: ولاجن جدول رقم (3) المتوسطات الحسابية والانحرافات المعيارية الخاصية بدور البيئة المدرسية في زيادة التحصيل الدراسي لدى طلبة المرحلة الأسساسية في مدارس مدينة المفرق من وجهة نظر معلميها

\begin{tabular}{|c|c|c|c|c|}
\hline الدور & 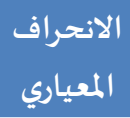 & المتوسط & 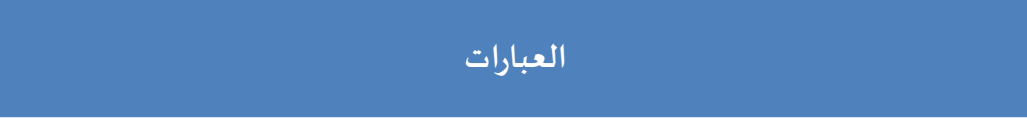 & $\hat{\imath}$ \\
\hline كبير & 0.556 & 4.63 & استخدام استراتيجيات التعليم الحديثة يسهم في زيادة تحصيل الطلبة & 1 \\
\hline كبير & 0.621 & 4.61 & استخدام وسائل التكنولوجيا في التعليم يساعد على زيادة تحصيل الطلبة & 2 \\
\hline كبير & 0.724 & 4.59 & تسهم الزيارات الميدانية في تعميق فهم الطلبة وهذا يؤدي إلى رفع مستوياتهم العلمية & 3 \\
\hline كبير & 0.568 & 4.58 & استخدام المدرسة لأساليب التحفيز لطلبتها عامل مساعد لارتفاع تحصيل الطلبة & 4 \\
\hline كبير & 0.568 & 4.56 & اعتماد المعلم على الوسائل التعليمية في توضيع المادة يسهم في رفع مستوى تحصيل & 5 \\
\hline
\end{tabular}




\begin{tabular}{|c|c|c|c|c|}
\hline الدور & الانحراف & المتوسط الحسابي & 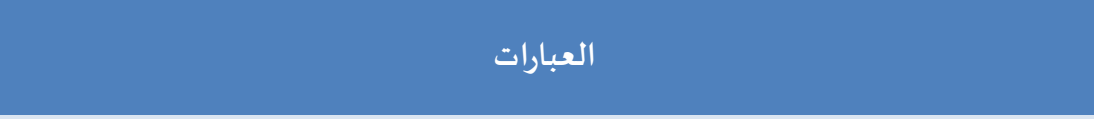 & $\hat{\imath}$ \\
\hline & & & 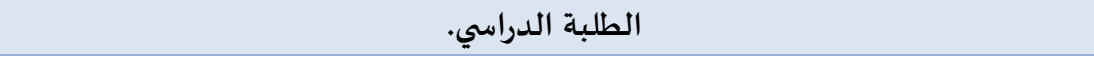 & \\
\hline كبير & 0.571 & 4.54 & استخدام المدرسـة لأسـاليب التشجيع لطلبتها عامل مسـاعد لارتفاع تحصيل الطلبة & 6 \\
\hline كبير & 0.681 & 4.52 & الديمقراطية فيما بين الطلبة له أثرفي زيادة التحصيل الدراسي. & 7 \\
\hline \multirow[t]{2}{*}{ كبير } & 0.629 & 4.48 & ارتباط المدرسة بالأسرة من العوامل التي تؤدي إلى ارتفاع مستوى تحصيل الطلبة. & 8 \\
\hline & 0.629 & 4.46 & قلة عدد الطلبة في الفصل يسـاعد في ارتفاع تحصيل الطلبة. & 9 \\
\hline كبير & 0.626 & 4.44 & الخوف داخل المدرسـة من عوامل تدني مستوى التحصيل. & 10 \\
\hline كبير & 0.774 & 4.42 & العدل فيما بين الطلبة له أثرفي زيادة التحصيل الدراسي. & 11 \\
\hline كبير & 0.675 & 4.40 & احتواء المدرسة على مرافق مجهزة يساعد الطلبة في رفع تحصيلهم الدراسي. & 12 \\
\hline كبير & 0.615 & 4.37 & القلق داخل المدرسة من عوامل تدني مستوى التحصيل. & 13 \\
\hline كبير & 0.711 & 4.33 & ضعف الأمن النفسي داخل المدرسة من عوامل تدني مستوى التحصيل. & 14 \\
\hline كبير & 0.640 & 4.28 & النصاب العالي من الحصص تؤثر سلبا على تحصيل الطلبة. & 15 \\
\hline كبير & 0.868 & 4.26 & ممارسة المدرسة للأنشطة اللاصفية تعزز تحصيل طلبتها. & 16 \\
\hline كبير & 0.887 & 4.20 & وجود مرشـد طلابي متخصص بالمدرسة يساعد في تعزيز تحصيل الطلبة. & 17 \\
\hline كبير & 0.937 & 4.13 & المدرسة التي تهتم بعقد مجالس الآباء تكون علاقة الآباء بالمعلمين قوية وهذا ينعكس على الطلى & 18 \\
\hline كبير & 0.964 & 3.97 & اسنـاد بعض المسؤوليات للمعلم تؤثر سلبا على تحصيل الطلبة. & 19 \\
\hline كبير & 1.196 & 3.88 & استخدام المدرسة لأساليب غير تربوية اثناء معاقبة الطالب تؤثر سلبا على تحصيل & 20 \\
\hline كبير & 0.973 & 3.86 & محاولة تطبيق المواد النظرية بطريقة عملية يساعد في زيادة تحصيل الطلبة. & 21 \\
\hline كبير & 0.819 & 3.85 & المدرسة ذات البيئة الصفية الجذابة طلابها هم الاعلى تحصيلا. & 22 \\
\hline كبير & 1.064 & 3.81 & ممارسـة المدرسة للأنشطة الصفية تعزز تحصيل طلبتها. & 23 \\
\hline متوسط & 0.884 & 3.67 & كفاءة الهيئة الادارية بالمدرسة تؤثر إيجابا على التحصيل الدراسي. & 24 \\
\hline متوسط & 0.932 & 3.60 & المدرسة ذات البيئة الصفية الممتعة طلابها هم الاعلى تحصيلاً. & 25 \\
\hline متوسط & 1.040 & 3.43 & توفير عنصر النظافة في المدرسة يجلب الاستقرار للطلبة وهذا ينعكس إيجابا على تحصيل & 26 \\
\hline متوسط & 0.925 & 3.20 & الاعتماد على اسلوب التشجيع عوضا عن العقاب يسهم في دفع الطلبة لزيادة تحصيلهم & 27 \\
\hline متوسط & 0.999 & 3.03 & بناء خطط المعلمين بالاعتماد على كون الطالب محور العملية التعليمية يسهم في رفع التحصيل الدراسي لديهم. & 28 \\
\hline متوسط & 1.015 & 2.73 & التنويع في أساليب تقييم الطلبة له دور كبير في زيادة التحصيل الدراسي لديهم. & 29 \\
\hline قليل & 0.774 & 2.23 & التقليل من عبئ الواجبات المدرسية يرفع تحصيل الطلبة. & 30 \\
\hline كبير & 0.46838 & 4.03 & الدرجة الكلية & \\
\hline
\end{tabular}

يتضح من خلال البيانات في الجدول السـابق أن دور البيئة المدرسية في زيادة التحصيل الدراسي لدى طلبة

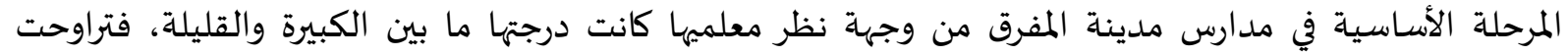

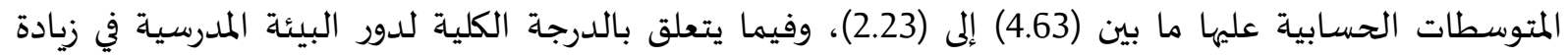

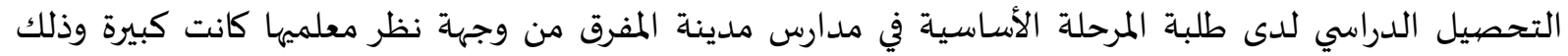

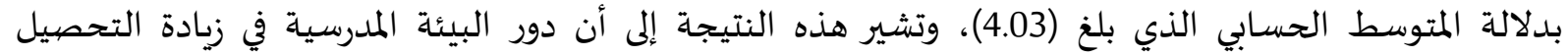


الدراسي لدى طلبة المرحلة الأساسية في مدارس مدينة المفرق من وجهة نظر معلميها كبيرة حسب المقياس المعد

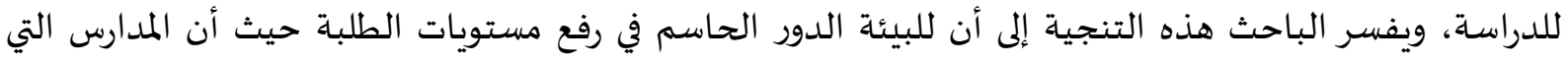

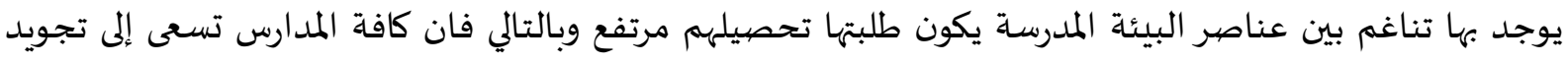

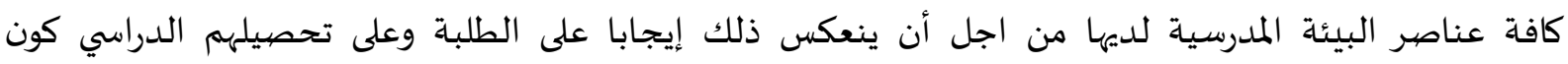

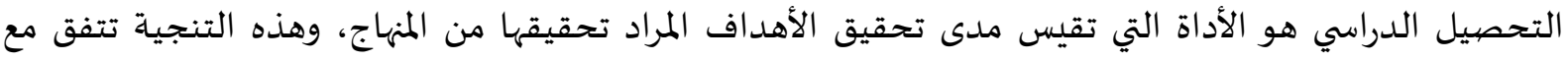

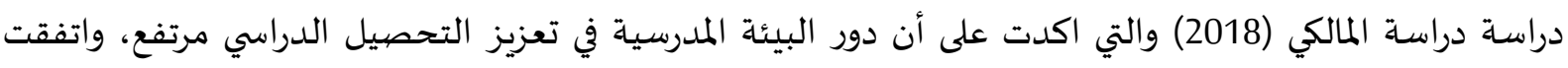

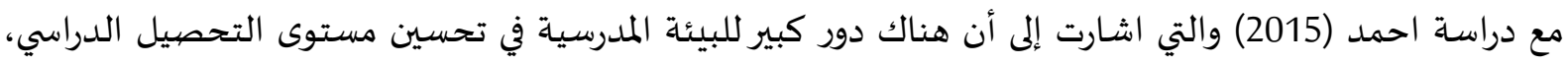

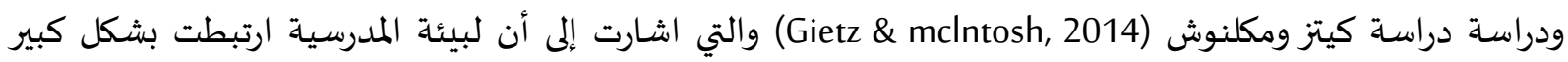
بالنجاح الأكاديمي لدة الطلبة.

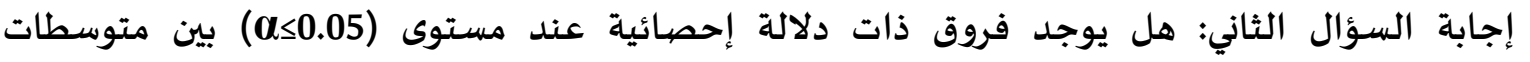

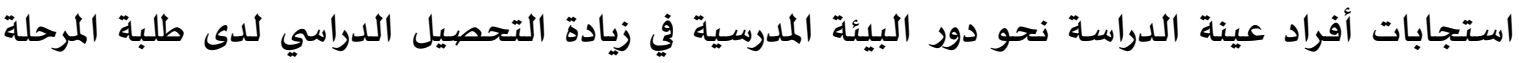

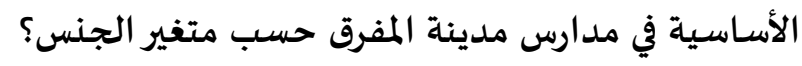

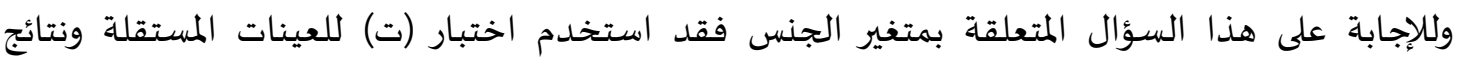
الجدول التالي توضح ذلك:

جدول رقم (4) نتائج اختبار(ت) للعينات المستقلة لدلالة الفروق في دور البيئة المدرسية في زيادة التحصيل

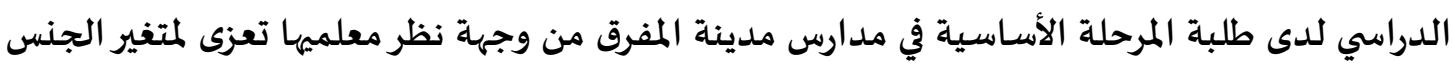

\begin{tabular}{|c|c|c|c|c|c|c|}
\hline مستوى الدلالة** & قيمة(ت) & الانحراف & المتوسط & العدد & النوع & المتخير \\
\hline \multirow[t]{2}{*}{0.40} & \multirow{2}{*}{0.848} & 0.47030 & 4.0077 & 15 & ذكر & \multirow{2}{*}{ لجنس } \\
\hline & & 0.34694 & 4.2167 & 15 & أنثى & \\
\hline
\end{tabular}

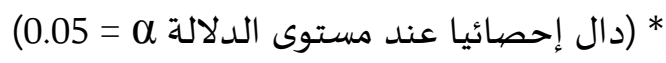

نلاحظ من خلال البيانات الواردة في الجدول السابق عدم وجدود فروق ذادئ ذات دلاتلة إحصائية عند مستوى الدلالة (0.05) في متوسطات استجابات أفراد عينة الدراسة نحو دور البيئة المدرسية في زيادة التحصيل الدراسي

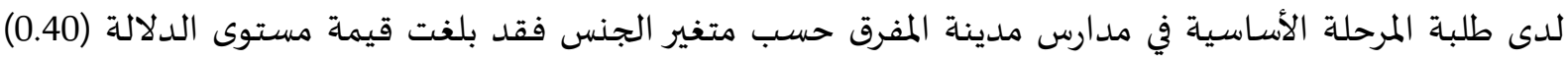

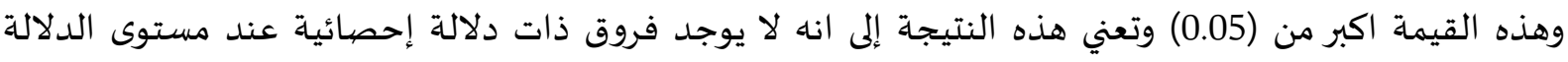

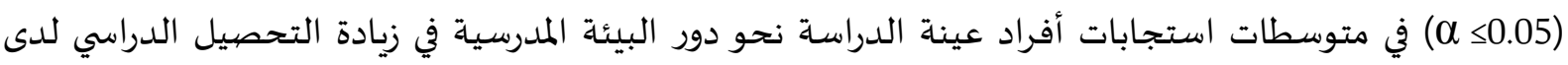

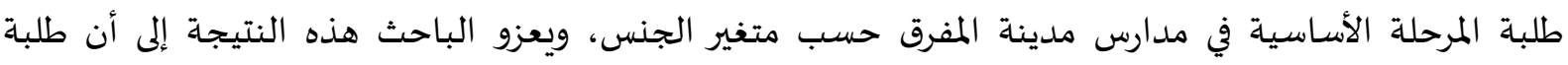

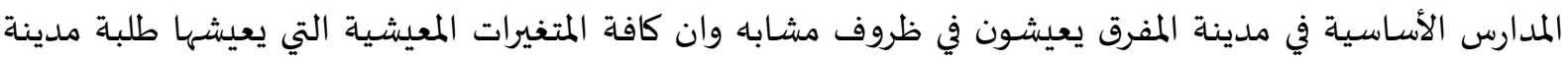
المفرق متشابهة وذلك بعض النظرعن جنسهم ولهذا تبين أن لا يوجد فروق في استجابات معلمي المدارس فيما يتعلق

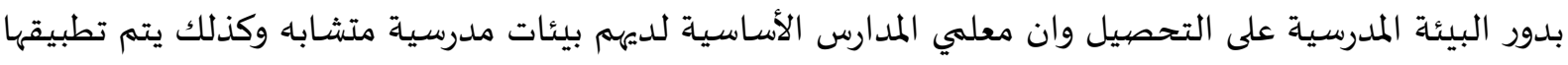

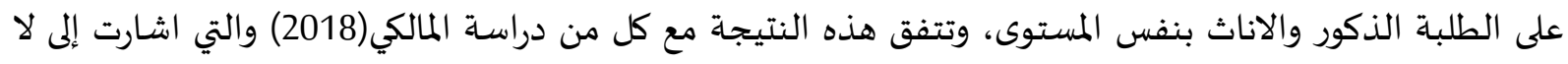
يوجد فروق ذات دلالة إحصائية في دور البيئة الأسرية والمدرسية في تعزيز التئ التحصيل الدراسي لدئ لدى طلاب المئ المرحلة الابتدائية تعزى لمتغير الجنس. 
إجابة السؤال الثالث: هل يوجد فروق ذات دلالة إحصائية عند مستوى (x 0.05$)$ في متوسطات

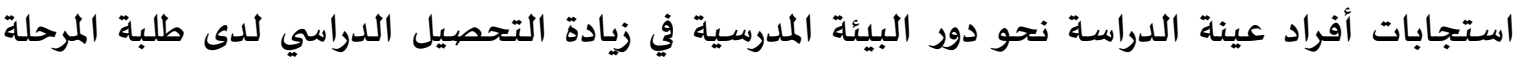

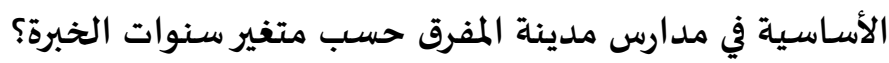

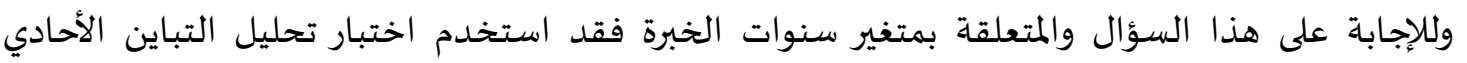
والجدول (5) يوضح ذلك:

الجدول (5) اختبار تحليل التباين الأحادي لدلالة الفروق بين متوسطات استجابات أفراد عينة الدراسـة نحو

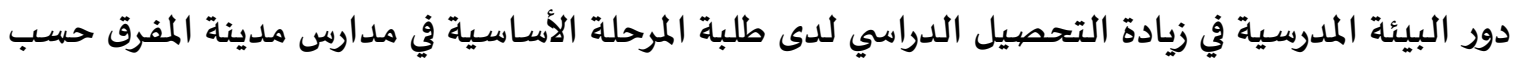
متغير سنوات الخبرة تعزى لمتغير سنوات الخبرة

\begin{tabular}{|c|c|c|c|c|c|c|}
\hline مستوى الدلالة & قيمة(ف) & متوسط المربعات & الحرية درجة & المربعات & مصددر التباين & المحور \\
\hline \multirow[t]{3}{*}{0.708} & 0.350 & 0.076 & 3 & 0.153 & بين المجموعات & \multirow{3}{*}{ سنوات الخبرة } \\
\hline & & 0.218 & 26 & 5.889 & داخل المجموعات & \\
\hline & & & 29 & 6.042 & المجموع & \\
\hline
\end{tabular}

(دال إحصائيا عند مستوى الدلالة $\alpha$ = 0.05) *

يلاحظ من خلال البيانات الواردة في الجدول السابق عدم وجود فروق ذات دلاتلاتلة إحصائية عند مستوى الدلالة (0.05) في متوسطات استجابات أفراد عينة الدراسة نحو دور البيئة المدرسية في زيادة التحصيل الدراسي لدى طلبة المرحلة الأسساسية في مدارس مدينة المفرق حسب متغير سنوات الخبرة، فقد بلغت قيمة مستوى الدلالة (0.70) وهذه القيمة اكبر من (0.05) وتوكد هذه النتيجة على عدم وجود فروق ذات دات دلالة إحصائية عند مستوى منائه

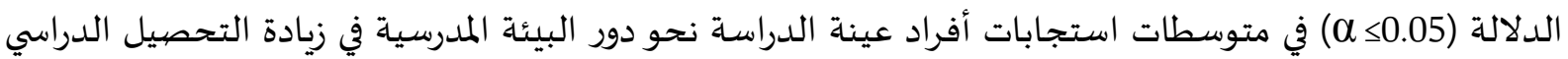

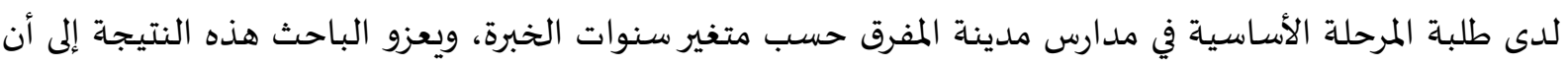

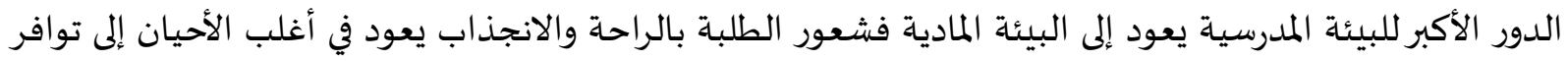

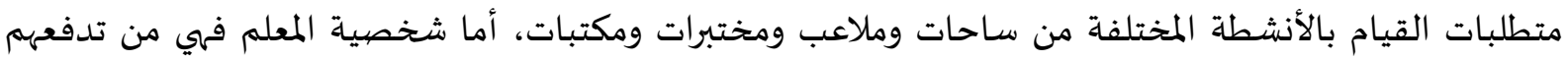

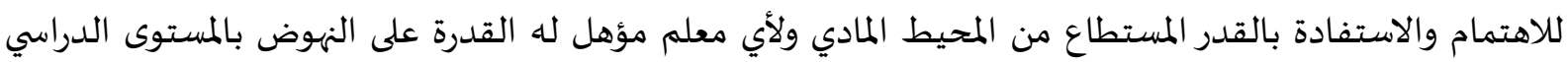

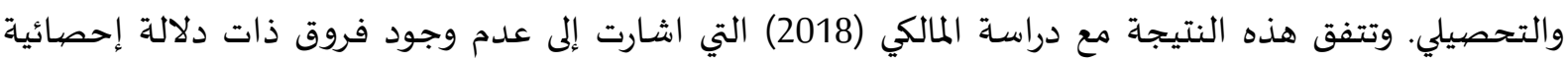

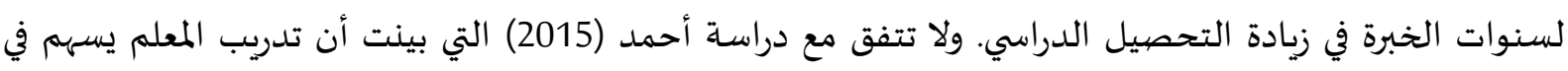
تحسين مستوى التحصيل الدراسي.

إجابة السؤال الرابع: هل يوجد فروق ذات دلالة إحصائية عند مستوى (o <0.05) في متوسطات استجابات

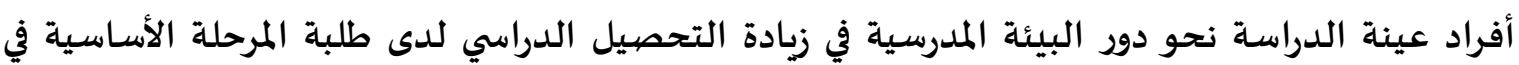
مدارس مدينة المفرق حسب متغير المؤهل العلمي؟ المرا؟

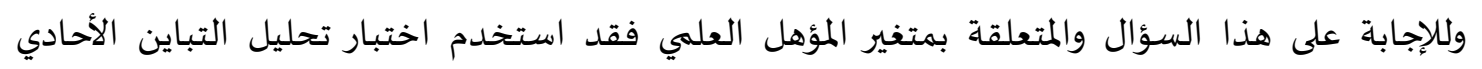
والجدول (6) يوضح ذلك علك ابه 
الجدول (6) اختبار تحليل التباين الأحادي لدلالة الفروق بين متوسطات استجابات أفراد عينة الدراسة نحو

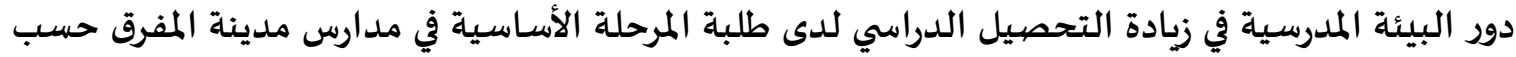

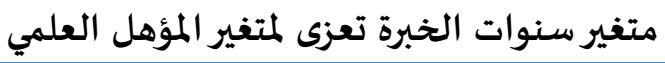

\begin{tabular}{|c|c|c|c|c|c|c|}
\hline مستوى الدلالة & قيمة(ف) & متوسط المربعات & درجة & المربعات & مصدر التباين & المحور \\
\hline \multirow[t]{3}{*}{0.256} & 1.433 & 0.290 & 2 & 0.580 & بين المجموعات & \multirow{3}{*}{ المؤهل العلهي } \\
\hline & & 0.202 & 27 & 5.462 & داخل المجموعات & \\
\hline & & & 29 & 6.042 & المجموع & \\
\hline
\end{tabular}

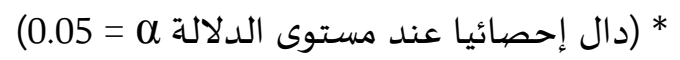

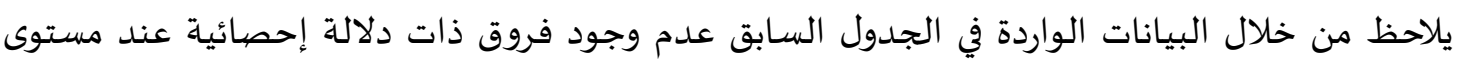

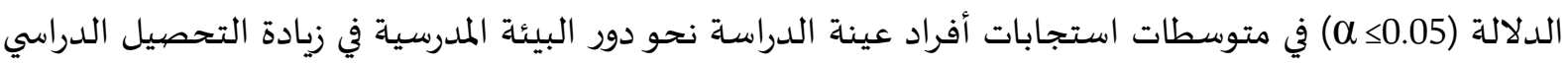
لدى طلبة المرحلة الأساسية في مدارس مدينة المفرق حسب متفير المؤهل العلمي فقد بلغت قيمة مستوى الدلالة

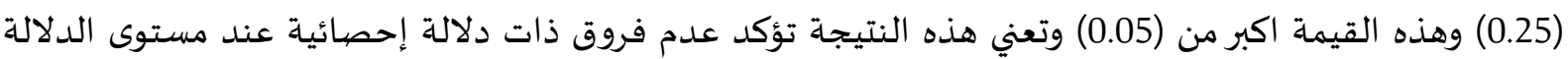

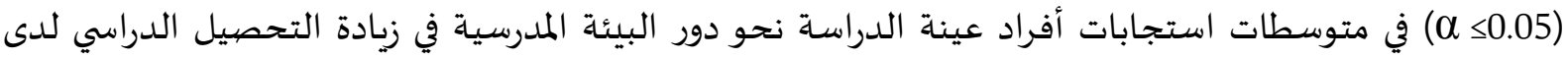

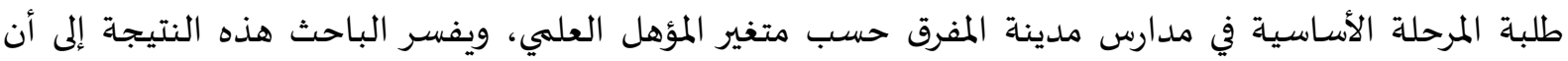

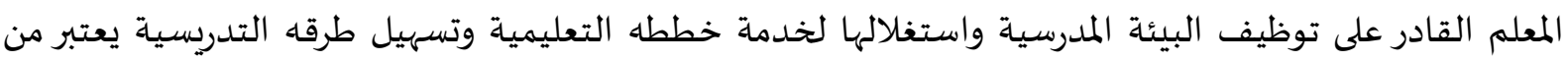
صفاته الشخصية ودافعيته الإيجابية نحو مهنة التدريس بغض النظرعن طبيعة المؤهل العلمي الذي يمتلكاه، فهذهاه

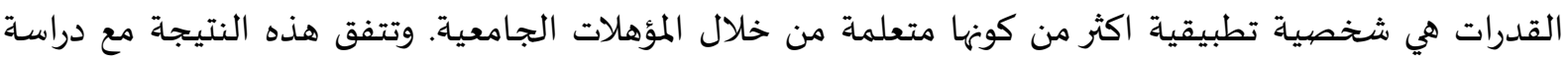

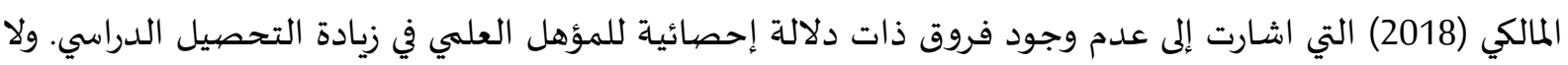

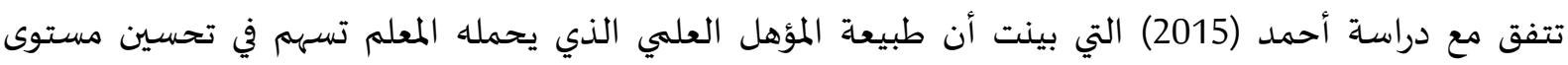
التحصيل الدراسي للطلبة.

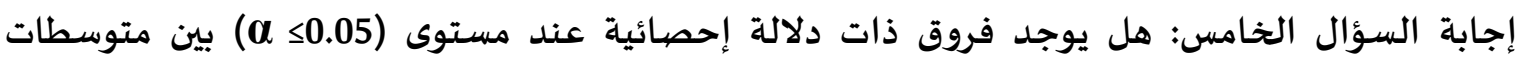

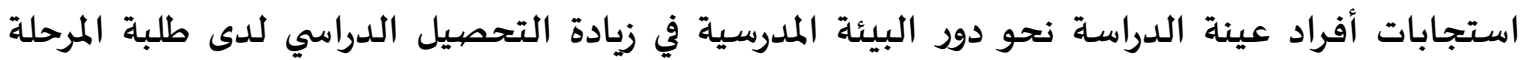

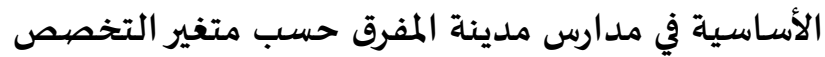

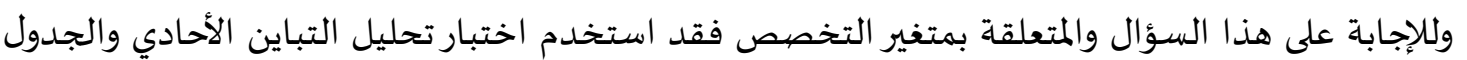
(7) يوضح ذلك الجدول (7) اختبار تحليل التباين الأحادي لدلالة الفروق بين متوسطات استجابات أفراد عينة الدراسة نحو

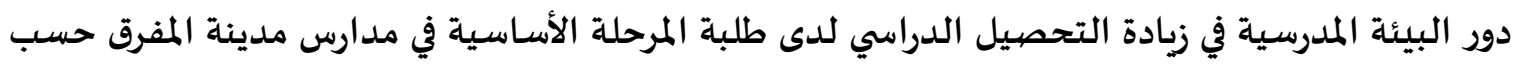
متغير التخصص

\begin{tabular}{|c|c|c|c|c|c|c|}
\hline مستوى الدلالة & قيمة(ف) & متوسط المربعات & الحربة درجة & المربعات & مصيدر التباين & المحتور \\
\hline \multirow[t]{3}{*}{0.384} & 0.991 & 0.207 & 2 & 0.413 & بين المجموعات & \multirow{3}{*}{ التخصص } \\
\hline & & 0.208 & 27 & 5.629 & داخل المجموعات & \\
\hline & & & 29 & 6.042 & المجموع & \\
\hline
\end{tabular}




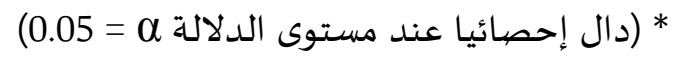

يلاحظ من خلال البيانات الواردة في الجدول السابق عدم وجود فروق ذات ذات دلالة إحصائية الحساية عند مستوى الدلالة (x<0.05) بين في متوسطات استجابات أفراد عينة الدراسة نحو دور البيئة المدرسية في زيادة التحصيل الدراسي لدى طلبة المرحلة الأساسية في مدارس مدينة المفرق حسب متغير التخصص، فقد فلد بلغت قيمة مستوى

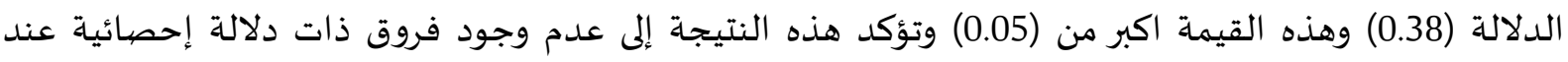
مستوى الدلالة (0.05) بين متوسطات استجابات أفراد عينة الدراسة نحو دور البيئة المدرسية في زيادة التحصيل

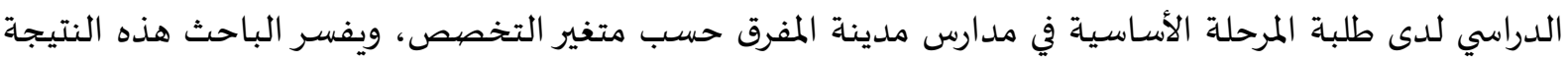

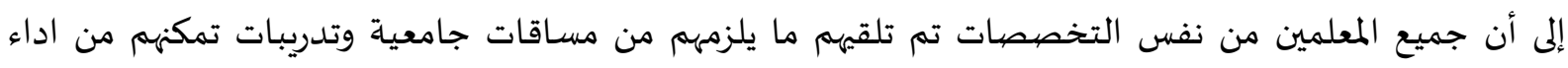
واجبهم التعليهي تجاه طلبتهم بطريقة جيدة، فلكل منهم تخصصيه وطبيعة هذا التخصص، المعا مهارة الاستغلال

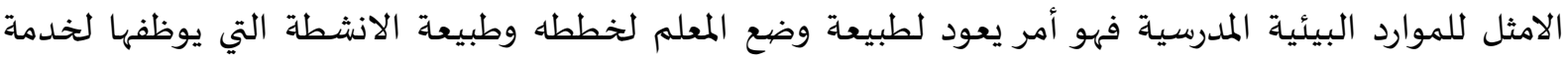

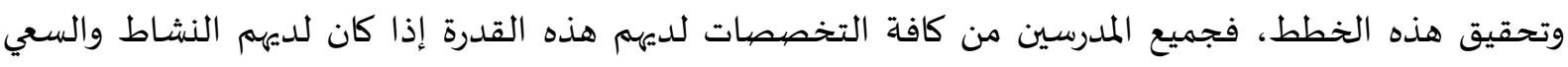

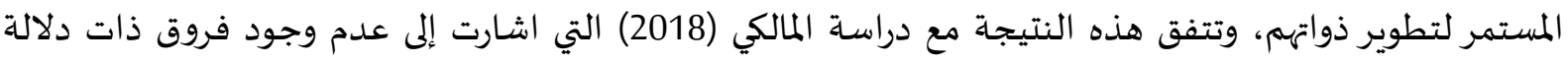
إحصائية لمتغير التخصص في زيادة التحصيل الدراسي. ولم تعترض هذه النتيجة مع مع من من نتائج الدراسات السابقة الواردة في هذه الدراسـة.

التوصيات والمقترحات.

وبناء على نتائج الدراسة بوصي الباحث ويقترح بما يلي:

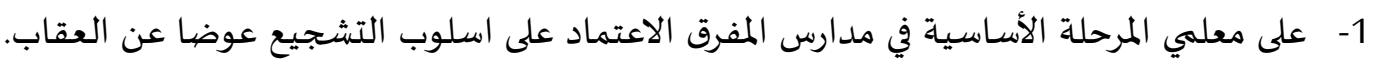
2- على المعلمين بناء خططهم بالاعتماد أن الطالب محور العملية التعليمية وليس اتباع نظام المنهاج القديم.

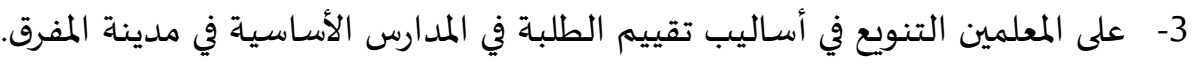

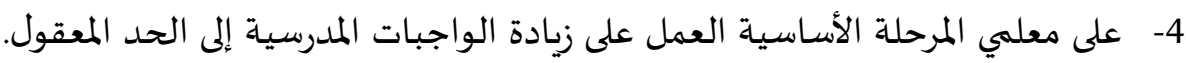

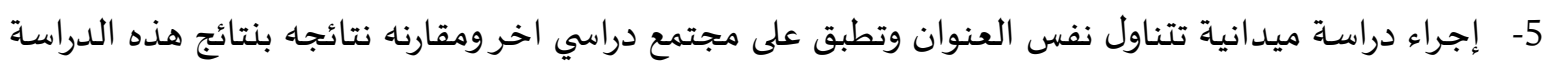

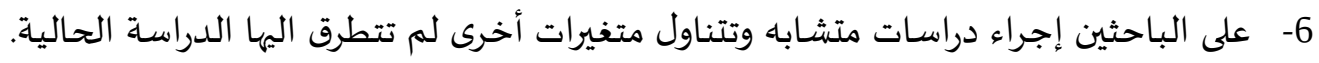

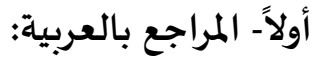

- أحمد، أميرة (2015). دور البيئة المدرسية في تحسين مستوى التحصيل الدراسي في مرحلة التعليم الاساسي

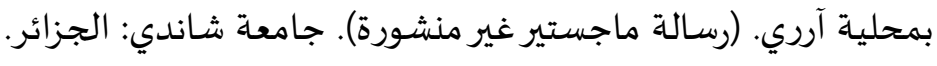

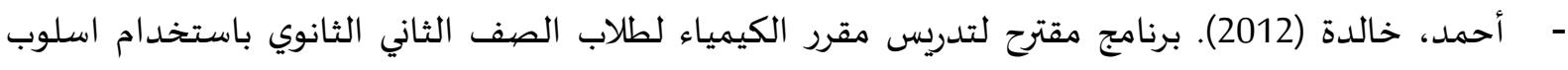

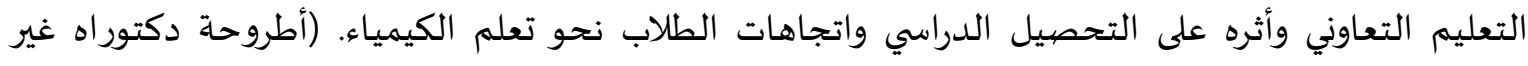

$$
\text { منشورة). جامعة الخرطوم: السودان. }
$$

- ـ الاسطل، محمد (2010). العوامل المؤدية إلى تدني التحصيل في الرياضيات لدى تلامذة المرحلة الأساسية العليا

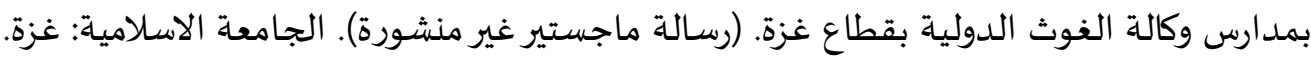
- الاهلي، أحمد (2015). البيئة المدرسية. مجلة موسوعاة البئة البئة. 
برور، محمد (2010). أثر التوجيه المدرسي على التحصيل الدراسي في المرحلة الثانوية. دار الأمل للطباعة والنشر: الجزائر. جروان، فتحي (2011). تعليم التفكير مفاهيم وتطبيقات. الطبعة الخامسـة، دار الفكر: عمان. - جروان، فتحي (2016). الموهبة والتفوق. دار الكتاب الجامعي: الامارات العربية المتحدة.

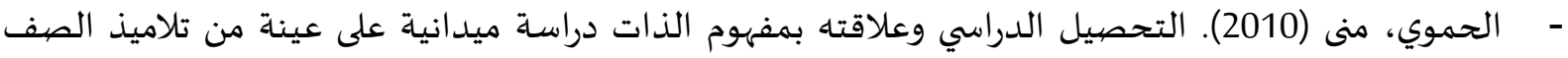

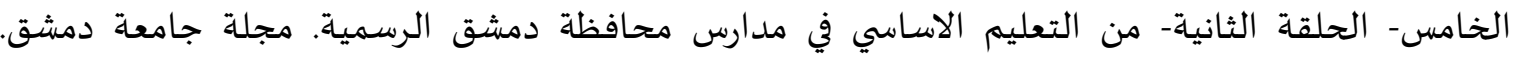
$.193-176.12(26)$

- ـ الخليفة، مدثر (2010). البيئة المدرسية وعلاقتها بالتحصيل الدراسي لطلاب مرحلة الأساس بمحلية المتمة. (رسالة ماجستير غير منشورة). جامعة شاندي: الجزائر.

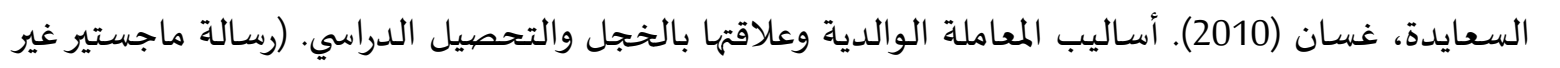
منشورة). جامعة مؤته: الأردن. عفانه، حنان (2018). دور الادارة المدرسية في تحقيق البيئة المدرسية الآمنة المحففزة في مدارس الأنروا في المحافظات الجنوبية. (رسالة ماجستير غير منشورة). جامعاة الأزهر: غزة الهان. - العقون، صالح (2011). البيئة الاجتماعية المدرسية وعلاقهها بالتحصيل الدراسي. (رسالة ماجستير غير منشورة). جامعة محمد خيضر: بسكرة. قمر الدين، عبد العظيم؛ وخليفة، علي؛ وأحمد، ابراهيم (2010). واقع البيئة المدرسية بمرحلة التعليم الأسـاسي. دراسات تربوية. (21)210 210-235. محمد، عالية (2017). المناخ المدرسي وعلاقته بدافعية الإنجاز لطلاب وطالبات المرحلة الثانوية بأم درمان. المجلة العلمية لكلية التربية. (22)2. 426-464. محمود، عبد الهادي (2013). دور البيئة المدرسية في الأداء الأكاديمي لدى تلاميذ مرحلة الأساس. (رسالة

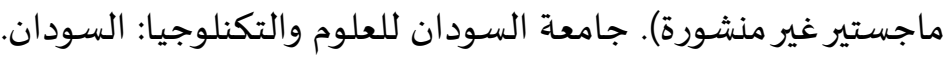
مضيوي، فؤاد (2012). أثر البيئة المدرسية في التحصيل الدراسي. (رسالة ماجستير غير منشورة). جامعة السودان المفتوحة: السودان. الملكي، أحمد (2018). دور البيئة الأسرية والمدرسية في تعزيز التحصيل الدراسي لدى طلاب المرحلة الابتدائية من وجهة نظر المعلمين. المجلة العربية للآداب والدراسات الانسانية. (5)3. 157-175.

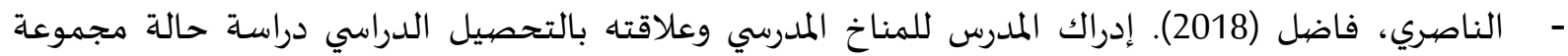

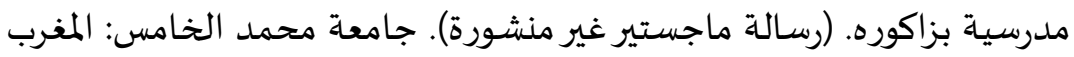

\section{ثانياً - المراجع بالإنجليزية:}

- Gietz. C, mclntosh. K. (2014). Relations Between Student Perceptions of Their School Environment and Academic Achievement. Canadian Journal of School Psychology. 9(3),311-345.

- Grete. D, Violence, bullying and academic achievement: A study of 15-year-old adolescents and their school environment. Child Abuse \& Neglect. 37(4).321-348.

- Lawrence, A. Vimala, A. (2012). School Environment and Academic Achievement of Standard ix Students. Journal of education and instructional studies in the world,1(2),129-147. 
- Nancy. G, Murray. D, Barbara. J, Christine. H, CHE.A, Alan. W, Cross. M, Davis. M, (2015). Coordinated School Health Programs and Academic Achievement: A Systematic Review of the Literature. Journal of School Health. 4(3),233-254.

- Wang. M, Holcombe. R, (2010). Adolescents' Perceptions of School Environment, Engagement, and Academic Achievement in Middle School. American Educational Research Journal. (47)3. 